\title{
Cryo-EM structure of the human NKCC1 transporter reveals mechanisms of ion coupling
} and specificity.

Caroline Neumann ${ }^{1,2}$, Lena Lindtoft Rosenbæk ${ }^{3}$, Rasmus Kock Flygaard ${ }^{1,2}$, Michael Habeck ${ }^{1,2}$, Jesper Lykkegaard Karlsen ${ }^{2}$, Yong Wang ${ }^{4,5}$, Kresten Lindorff-Larsen ${ }^{4}$, Hans Henrik Gad ${ }^{2}$, Rune Hartmann $^{2}$, Joseph Lyons ${ }^{1,2}$, Robert A. Fenton ${ }^{3 *}$, Poul Nissen ${ }^{1,2^{*}}$

1 Danish Research Institute of Translational Neuroscience - DANDRITE, Nordic EMBL Partnership for Molecular Medicine.

2 Department of Molecular Biology and Genetics, Aarhus University, 8000 Aarhus, Denmark.

3 Department of Biomedicine, Aarhus University, 8000 Aarhus, Denmark.

4 Linderstrøm-Lang Centre for Protein Science, Department of Biology, University of Copenhagen, 2200 Copenhagen, Denmark.

5 Shanghai Institute for Advanced Study, Institute of Quantitative Biology, College of Life Sciences, Zhejiang University, Hangzhou 310027, China

* Corresponding authors. E-mails: robert.a.fenton@biomed.au.dk (RF); pn@mbg.au.dk (PN)

\begin{abstract}
The sodium-potassium-chloride transporter NKCC1 (SLC12A2) performs $\mathrm{Na}^{+}$-dependent $\mathrm{Cl}^{-}$and $\mathrm{K}^{+}$ion uptake across plasma membranes. NKCC1 is important for regulating e.g. cell volume, hearing, blood pressure, and chloride gradients defining GABAergic and glycinergic signaling in brain. Here, we present a $2.6 \AA$ resolution cryo-electron microscopy (cryo-EM) structure of human NKCC1 in the substrate-loaded $\left(\mathrm{Na}^{+}, \mathrm{K}^{+}, 2 \mathrm{Cl}^{-}\right)$and inward-facing conformation adopting an occluded state that has also been observed for the SLC6 type transporters MhsT and LeuT. $\mathrm{Cl}^{-}$ binding at the $\mathrm{Cl1}$ site together with the nearby $\mathrm{K}^{+}$ion provide a crucial bridge between the LeuTfold scaffold and bundle domains. $\mathrm{Cl}^{-}$ion binding at the $\mathrm{Cl} 2$ site seems to undertake a structural role similar to a conserved glutamate of SLC6 transporters and may allow for chloride-sensitive regulation of transport. Supported by functional studies in mammalian cells and computational simulations we describe the $\mathrm{Na}^{+}$binding site and a putative $\mathrm{Na}^{+}$release pathway along transmembrane helix 5. The results provide insight into the structure-function relationship of NKCC1 with broader implications for other SLC12 family members.
\end{abstract}

Keywords: chloride transport / cation:chloride co-transporters / NKCC1 / ion coupling / substrate specificity / cryo-EM 


\section{Introduction}

Eukaryotic cation:chloride co-transporters (CCCs) belonging to the SLC12 family can be divided into three subclasses: the sodium:potassium:chloride (NKCCs, SLC12A1-2), sodium:chloride (NCC, SLC12A3) and potassium:chloride (KCCs, SLC12A4-7) co-transporters. Furthermore, there are two orphan transporters CCC9 (SLC12A8) and CIP1 (SLC12A9) (Arroyo et al, 2013). The $\mathrm{Cl}^{-}$ translocation by CCCs is secondary active, driven by $\mathrm{Na}^{+}$and/or $\mathrm{K}^{+}$gradients established by the plasma membrane $\mathrm{Na}^{+}-\mathrm{K}^{+}$-ATPase (Markadieu \& Delpire, 2014; Payne, 2012). NKCCs transport $\mathrm{K}^{+}$and $\mathrm{Cl}^{-}$into cells coupled to $\mathrm{Na}^{+}$influx, $\mathrm{NCC}$ transports $\mathrm{Na}^{+}$and $\mathrm{Cl}^{-}$into cells, whereas $\mathrm{KCCs}$ extrude $\mathrm{K}^{+}$and $\mathrm{Cl}^{-}$out of cells (Hebert et al, 2004). All the characterized co-transporters are electroneutral and are important for maintaining cellular $\mathrm{Cl}^{-}$balance and cell volume in numerous different cell types (Delpire \& Gagnon, 2018). NCC and NKCC2 activity in the kidney are important for maintenance of $\mathrm{NaCl}$ homeostasis and hence blood pressure regulation (Arroyo et al., 2013), with NKCC2 also important for $\mathrm{NH}_{4}{ }^{+}$reabsorption and acid-base homeostasis (Markadieu \& Delpire, 2014). Maintenance of cellular $\mathrm{Cl}^{-}$balance by CCCs in the central nervous system is not only important for neuronal proliferation and differentiation, but it determines the strength of inhibitory, hyperpolarizing neurotransmission by glycine- and GABA-gated chloride channels, respectively (Blaesse et al, 2009) or even reverse polarities. NKCC1 also inhibits the leucine transporter LAT1 and Akt/Erk pathways and mTORC1 activation (Demian et al, 2019), thereby creating a connection between cell volume and cell mass regulation. The importance of CCCs is highlighted by numerous diseases, with inactivating mutations of NKCC2 leading to type I Bartter's syndrome (Simon et al, 1996a), mutations of NCC causing Gitelman syndrome (Ji et al, 2008; Simon et al, 1996b), both characterized by reduced $\mathrm{K}^{+}$levels in blood and elevated blood $\mathrm{pH}$. Mutations of KCC3 cause Andermann syndrome, a severe neurodegenerative disorder (Arroyo et al., 2013). NKCC1 mutations are also linked to impaired hearing and neurodevelopment (Koumangoye et al, 2021). Furthermore, improper functioning of CCCs are associated with various neurological and psychiatric disorders, such as epilepsy, neuropathic pain, anxiety, cerebral ischemia, autism and schizophrenia (Jaggi et al, 2015).

Recently, cryo-EM structures of the dimeric NKCC1 (Chew et al, 2019; Yang et al, 2020; Zhang et al, 2021), KCC1 (Liu et al, 2019), KCC2 (Chi et al, 2021; Xie et al, 2020), KCC3 (Xie et al., 2020) (Chi et al, 2020) and KCC4 (Xie et al., 2020) transporters as well as a monomeric structure of 
bioRxiv preprint doi: https://doi.org/10.1101/2021.11.11.468215; this version posted November 12, 2021. The copyright holder for this preprint (which was not certified by peer review) is the author/funder, who has granted bioRxiv a license to display the preprint in perpetuity. It is made available under aCC-BY-NC 4.0 International license.

KCC4 (Reid et al, 2020) have described the three-dimensional architecture of these transporters, their fold and the potential localization of their $\mathrm{Na}^{+}$and/or $\mathrm{Cl}^{-}$binding sites. All these structures present the transporters in their partially occluded inward-facing conformation with substrates still occupying the binding pockets. They contain 12 transmembrane (TM) helices with an inverted pseudo-twofold symmetry between TM1-5 and TM6-10, first identified as the LeuT-fold (Yamashita et al, 2005). TM helices 1 and 6 contain non-helical junctions in the middle that allow for independent movement of the intracellular and extracellular halves to expose or close the substrate-binding sites to solvent access in an 'alternating access' manner (Joseph et al, 2019). Despite coming from two distinct vertebrates with only $74.2 \%$ sequence identity, the $\mathrm{K}^{+}$and $\mathrm{Cl}^{-}$ binding sites in zebrafish (Danio rerio, zNKCC1) and human NKCC1 (hNKCC1) are fully conserved, highlighting the importance of specific residues for interacting with the transported ions (Chew et al., 2019; Yang et al., 2020). The regulatory N-terminal domain in hNKCC1 is 77 amino acid residues longer than in zNKCC1 (285 vs 208 residues) and is disordered in nature ${ }^{12}$. Crystal structures of the regulatory $\mathrm{C}$-terminal domain of a bacterial $\mathrm{NKCC} 1$ homologue (Warmuth et al, 2009) and of the eukaryotic C-terminal domain of KCC1 have provided further insight into the regulatory mechanisms of CCC transporters (Zimanyi et al, 2020).

Structural studies of amino acid-polyamine-organocation (APC) transporters adopting the LeuT fold have provided extensive insight and understanding of their transport mechanisms, substrate specificity, ion coupling and inhibitory action. Since the first LeuT crystal structure (Yamashita et al., 2005), several other SLC6 structures (MhsT (Malinauskaite et al, 2014), dDAT (Penmatsa et al, 2013), SERT (Coleman et al, 2016), B0AT1 (Yan et al, 2020), GlyT (Shahsavar et al, 2021)) have been determined in a variety of different conformational states and in complex with substrates or inhibitors. Additionally, structures of sequence-unrelated, but LeuT fold adopting SLC families have also been described, e.g. vSGLT (SLC5) (Faham et al, 2008; Watanabe et al, 2010), GkApcT (SLC7) (Jungnickel et al, 2018), ScaDMT (SLC11) (Ehrnstorfer et al, 2014), NKCC1 (SLC12) (Chew et al., 2019; Yang et al., 2020; Zhang et al., 2021) and SiaT (SLC35) (Wahlgren et al, 2018). Interestingly, despite minimal sequence similarity between different APC transport families, mechanistic aspects of $\mathrm{Na}^{+}$dependent transport seem to be retained among many of them. All the transporters contain two domains: the bundle domain comprising TM 1-2 and TM 6-7 that performs the main conformational changes throughout the transport cycle, and the scaffold domain encompassing TM 3-4 and TM 8-9 that stays almost rigid throughout the functional cycle. This is 
bioRxiv preprint doi: https://doi.org/10.1101/2021.11.11.468215; this version posted November 12, 2021. The copyright holder for this

often referred to as a rocking bundle mechanism (Forrest et al, 2011; Forrest \& Rudnick, 2009). Ligand and ion binding sites are localized at the interface of the scaffold and bundle domain and binding/release of specific ligands control bundle movements and coupling (Zhang et al, 2018). For the well-characterized SLC6 transporters, binding of extracellular $\mathrm{Na}^{+}$at the $\mathrm{Na} 2$ site (which also corresponds to the expected $\mathrm{Na}^{+}$binding site of NKCC1) stabilizes outward-facing states, followed by subsequent binding of substrates at $\mathrm{S} 1$ and the $\mathrm{Na} 1$ site. The $\mathrm{Na}^{+}$and substrate bound state can then explore conformational changes towards the inward-facing state (Ben-Yona \& Kanner, 2009; Claxton et al, 2010; Fenollar-Ferrer et al, 2014; Kazmier et al, 2014; Tavoulari et al, 2016; Zhao et al, 2010), where $\mathrm{Na}^{+}$release from the $\mathrm{Na} 2$ site to the cytoplasm (Malinauskaite et al., 2014) leads further to the inward-open state, where substrates are released from the S1 and Na1 sites (Krishnamurthy \& Gouaux, 2012). The main substrate alone has no effect on the conformational state without sodium ions present, and the $\mathrm{Na} 2$ site is a crucial structural element for cytoplasmic occlusion and opening (Tavoulari et al., 2016).

Here, we present a cryo-EM structure of the full-length human NKCC1 transporter in an occluded, inward-oriented state in complex with $\mathrm{K}^{+}$, two $\mathrm{Cl}^{-}$ions and $\mathrm{Na}^{+}$(Fig. S1A-B). Using the highresolution maps coupled to functional analysis in mammalian cells we characterize the ion and solvent binding sites of $\mathrm{NKCC} 1$, and further explore substrate specificity, coupling and release of ions in NKCC1 and their relationship to other CCCs. We also investigate the potential function of the $\mathrm{Na}^{+}$release pathway leading to the cytoplasmic environment and make comparisons of the NKCC1 structure with SLC6 type transporters matching similar structural states and sites.

\section{Results}

\section{NKCC1 cryo-EM determination}

We collected cryo-EM data of hNKCC1, which combined with single-particle analysis, resulted in a $2.6 \AA$ reconstruction of the transmembrane domain of human NKCC1 in its occluded, inwardfacing, substrate-bound conformation. i.e. a state preceding release of substrates to the cytoplasm (Fig. 1A). In three individual data sets, single particle images were extensively cleaned through multiple rounds of 3D classification before high-resolution reconstructions were obtained from 3D auto-refinement of Bayesian polished particles. Inspection of the reconstructions from the 
bioRxiv preprint doi: https://doi.org/10.1101/2021.11.11.468215; this version posted November 12, 2021. The copyright holder for this

individual data sets revealed the same state of $\mathrm{hNKCC} 1$, thus we merged data into a single stack of 256,791 particle images to obtain a higher-quality reconstruction (Fig. EV1, EV2 and EV3). Similar to other NKCC1 cryo-EM structures (Chew et al., 2019; Yang et al., 2020; Zhang et al., 2021), the $\mathrm{N}$-terminal domain could not be identified in the map. The regulatory cytoplasmic domain (aa 7561212) appears to be flexible and despite extensive attempts for classification in cryoSPARC (Punjani et al, 2017) and the use of multibody refinement in RELION (Nakane et al, 2018), it

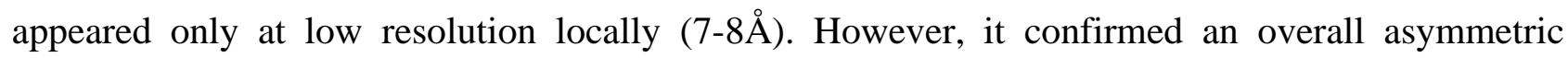
configuration of the transmembrane domains (Fig. 1A and EV3C). The cytoplasmic domains were masked out along with the detergent micelle and the refinement was focused on the transmembrane part of the transporter (Fig. EV1 and EV2).

The resolution of the final map was high enough to clearly identify non-protein features corresponding to a $\mathrm{K}^{+}$ion and two $\mathrm{Cl}^{-}$ions. Density at the $\mathrm{Na}^{+}$binding site appears at a lower, but significant contour level, indicating that the $\mathrm{Na}^{+}$site is also occupied and saturated at the $200 \mathrm{mM}$ $\mathrm{Na}^{+}$concentration of the purification buffer. When compared to the well-characterized SLC6 type amino acid transporters LeuT (Gotfryd et al, 2020) and MhsT (Malinauskaite et al., 2014), it is clear that despite different substrates the substrate binding sites are similar and hence the mechanisms of $\mathrm{Na}^{+}$coupled transport appear mutually informative.

\section{Lipid and cholesterol binding to hNKCC1}

The overall predicted LeuT-fold topology and dimeric architecture of the transmembrane region of the determined hNKCC1 are presented in Fig. 1B-C. Similar to zNKCC1 (Chew et al., 2019), our three-dimensional EM map revealed the presence of seven lipid molecules bound at the central cleft with either one or both acyl chains inserted between the two protomers (Fig. 1C-D). One lipid is placed directly on the $\mathrm{C} 2$ symmetry axis, whereas the remaining lipid molecules cluster in two pairs of 3 annular lipids found on opposite sides of the interface.

The EM map identified three cholesterol binding sites per NKCC1 protomer at the transporter surface, corresponding to the outer leaflet of the plasma membrane (Fig. 1C). Therefore, we decided to model cholesteryl hemisuccinate molecules (CHS, used in the solubilization and purification) into the densities. The first CHS molecule was found close to the dimer interface, binding at a groove formed between TM2 and TM6a with its $\alpha$-face forming a $\pi-\pi$ interaction with 
bioRxiv preprint doi: https://doi.org/10.1101/2021.11.11.468215; this version posted November 12, 2021. The copyright holder for this preprint (which was not certified by peer review) is the author/funder, who has granted bioRxiv a license to display the preprint in perpetuity. It is made available under aCC-BY-NC 4.0 International license.

F487 on TM6a. The CHS molecule is also accommodated by aromatic residues on TM6a (F488 and F491), in addition to F481 on EL3 and non-polar residues (L319, L322, V323, V329) on TM2 (Fig. 1E). The second CHS molecule interacts with hydrophobic residues on TM2 (V532, V534 and V538), TM5 (F449, V450 and F454) and F473 on EL3 and it forms a $\pi$ - $\pi$ interaction with Y468 on EL3 (Fig. 1F). A third potential CHS molecule was identified in close proximity, interacting hydrophobically with the second CHS molecule, the non-polar V450 and I451 on TM5 and forming a $\pi$ - $\pi$ interaction with F454 on TM5 (Fig. 1G). The molecule was, however, not modelled into the map. Assuming that hNKCC1 translocates its substrates using the rocking bundle mechanism similarly to other transporters adopting the LeuT-fold, the three CHS molecules appear to stabilize the inward-facing conformation of the transporter by both blocking movement of the extracellular parts of the bundle domain (TM2, TM5, TM6a) and disfavoring transitions to the outward-facing conformation with an open extracellular vestibule. Comparison of the unmodelled densities from the deposited KCC3 cryo-EM structure (Chi et al., 2021) reveal that all three cholesterol binding sites are conserved, despite different amino acid composition within these sites (Fig. S1D and E). A potential fourth cholesterol binding site could also be identified in KCC3 (Fig. S1F), where a cholesterol molecule can be accommodated in a groove formed by TM5 and TM7. Therefore, it seems that cholesterol might be of importance for both sodium-dependent and sodium-independent CCC transporters, stabilizing the substrate releasing state of NKCC1 and the substrate loading state of KCC transporters. These observations also support the association of both NKCC1 and KCC2 with cholesterol rich lipid rafts in the plasma membrane, where cholesterol could regulate their transport cycle (Hartmann et al, 2009).

\section{Sodium ion binding site and its role in ion coupling}

In hNKCC1, the $\mathrm{Na}^{+}$ion is coordinated by the main chain carbonyl oxygen of W300 and L297 on TM1 of the bundle domain, and the side chain hydroxyl groups of S613 and S614 and the main chain carbonyl oxygen of A610 on TM8 of the scaffold domain (Fig. 2A). This corresponds to the Na2 driver site of SLC6 type transporters like LeuT, dDAT, GlyT1, SERT and MhsT (Yamashita et al., 2005) (Fig. 2C). Contrasting the previously described zNKCC1 and hNKCC1 structures (Chew et al., 2019; Yang et al., 2020; Zhang et al., 2021), we consider the $\mathrm{Na}^{+}$bound hNKCC1 as an occluded inward-oriented conformation, which represents a trapped intermediate preceding $\mathrm{Na}^{+}$and subsequently $\mathrm{K}^{+}$and $\mathrm{Cl}^{-}$release to the cytoplasmic environment. When comparing our hNKCC1 to 
bioRxiv preprint doi: https://doi.org/10.1101/2021.11.11.468215; this version posted November 12, 2021. The copyright holder for this preprint (which was not certified by peer review) is the author/funder, who has granted bioRxiv a license to display the preprint in perpetuity. It is made available under aCC-BY-NC 4.0 International license.

the SLC6-type transporters MhsT and LeuT in forms that also adopt this inward-oriented and occluded state, we find striking similarities (Fig. 2C and Fig. S2). Most notably, we observe a clear candidate release pathway for $\mathrm{Na}^{+}$that extends from the $\mathrm{Na}^{+}$binding site to the cytoplasm along TM5. This pathway represents the critical, first encounter of the $\mathrm{Na}^{+}$site with the cytoplasmic environment, leading to subsequent solvation and release of $\mathrm{Na}^{+}$into the low-sodium cytoplasmic environment, hence defining the vectorial flow of transport. Defining the dynamics and functional properties of this pathway would provide key characteristics of NKCC1 function.

Water molecules are found within the intracellular vestibule, but in contrast to the occluded, inward-facing structure of MhsT (Malinauskaite et al., 2014), our hNKCC1 structure shows no solvation of the $\mathrm{Na}^{+}$site, like the occluded LeuT structures (Malinauskaite et al, 2016; Yamashita et al., 2005) (Fig. 2 and Fig. S3). The MOLE2.5 program was used to identify and analyze potential intracellular exit pathways (Berka et al, 2012) (Fig. 2E), as also described previously for hNKCC $1^{\text {K289N_G351R }}$ (Yang et al., 2020). Interestingly, intracellular pathway 1 is lined by E429 and E431 (predicted pKa-values of 4.6 and 4.5 by PROPKA, i.e. both negatively charged at pH 7.5) at the cytoplasmic interface (Fig. 3A). These residues are conserved in hNKCC1, hNKCC2 and hNCC, but absent in the sodium-independent KCC transporters (Fig. 3C). Thus, they may act as internal "gatekeepers" that attract the $\mathrm{Na}^{+}$ion from the binding site into the cytoplasmic environment, in a similar manner to as observed in cation channels (Doyle et al, 1998). Bacterial, but not mammalian, SLC6 transporters contain a conserved glutamate residue at a similar position to E429 (E192 $\left.{ }^{\text {LeuT }}\right)$ that interacts with and escorts the $\mathrm{Na}^{+}$out of the transporters (Shaikh \& Tajkhorshid, 2010) (Fig. 3B). This residue also corresponds to the conserved D182 in vSGLT (SLC5) that also facilitates $\mathrm{Na}^{+}$diffusion (Li \& Tajkhorshid, 2009). To probe further a putative role of $\mathrm{E} 429$ and $\mathrm{E} 431$ in $\mathrm{Na}^{+}$release for $\mathrm{hNKCC1}, \mathrm{Tl}^{+}$influx experiments (mimicking $\mathrm{K}^{+}$uptake) were performed in mammalian cells expressing wild-type hNKCC1 or various hNKCC1 mutants. The relative rate of $\mathrm{Tl}^{+}$influx was significantly lower for E429A, E431A and E431Q mutants when compared to wild-type hNKCC1. Additionally, there was no statistically significant difference between the relative transport rates of E431A (mutation to a non-polar residue without a negative charge) and E431Q mutants (mutation to a polar residue without a negative charge) (Fig. 3D). Together these results suggest important roles of E429 and E431 in hNKCC1 activity. Cell-surface expression of wild-type hNKCC1 and hNKCC1 mutants were not significantly different, indicating 
bioRxiv preprint doi: https://doi.org/10.1101/2021.11.11.468215; this version posted November 12, 2021. The copyright holder for this

that the altered activity observed with the mutants is not due to altered association of the mutant protein with the plasma membrane (Fig. EV4C-D).

The hNKCC1 structure revealed interactions between R294 on TM1a and Q435 on TM5 (Fig. 3A). Similar interactions are found in SLC6 structures with a sealed intracellular side, corresponding to the outward-oriented states of LeuT (Yamashita et al., 2005) and the occluded inward-facing structure of MhsT (Fig.3 and Fig. S3) (Malinauskaite et al., 2014). The arginine and glutamine residues in $\mathrm{hNKCC} 1$ are exclusively conserved in sodium-dependent CCCs suggesting that they are important for $\mathrm{Na}^{+}$transport, with potentially a similar function to SLC6 transporters (Fig. 3C). Consistent with this model, a R294A mutant has reduced transport activity relative to wild-type NKCC1 (Yang et al., 2020). K289 on TM1 is also conserved in the sodium-dependent CCCs, providing a potential interaction partner for one of the two conserved glutamate residues on TM5 in outward-facing conformational states, where the intracellular side is fully sealed.

Sequence alignment of the CCCs reveals no helix-breaking motif in the intracellular half of TM5, suggesting that TM5 stays intact in the SLC12 family, unlike for SLC6 transporters (Malinauskaite et al., 2014) (Fig. S4). This indicates that NKCC1, NKCC2 and NCC have different dynamics for $\mathrm{Na}^{+}$site solvation and $\mathrm{Na}^{+}$release, potentially involving a more pronounced movement of TM1a (Fig. S3).

\section{Coupling network within the main substrate binding pocket}

The substrate site in $\mathrm{hNKCC} 1$ accommodates a $\mathrm{K}^{+}$and $\mathrm{Cl}^{-}$ion, as previously demonstrated for the zNKCC1 (Chew et al., 2019), hNKCC1 (Zhang et al., 2021), hKCC1 (Liu et al., 2019), hKCC2 (Chi et al., 2020), hKCC3 (Chi et al., 2020) and hKCC4 (Reid et al., 2020; Xie et al., 2020) by coordination chemistry and molecular dynamics (MD) simulations. The $\mathrm{K}^{+}$ion is coordinated by the carbonyl oxygens of N298, I299, T499, P496 and the hydroxyl groups of Y383 and T499 (Fig. 4A). Y383 seems to have an important role in substrate specificity, as relative to NKCCs and KCCs, the conserved site in NCC (not transporting $\mathrm{K}^{+}$) is a histidine residue, which may substitute for $\mathrm{K}^{+}$(Fig. 4C) (Hartmann \& Nothwang, 2014). Previous functional studies demonstrated that mutation of the tyrosine residue results in impairment of transport of the human NKCC1 (Somasekharan et al, 2012). The corresponding $\mathrm{Y} 108^{\mathrm{LeuT}}$ and $\mathrm{Y} 176^{\text {SERT }}$ are crucial residues for substrate induced conformational change from the outward-facing to the inward-facing states in SLC6 transporters 
bioRxiv preprint doi: https://doi.org/10.1101/2021.11.11.468215; this version posted November 12, 2021. The copyright holder for this

and participate in an interaction network between the bundle (TM 6 and 7) and scaffold domain (TM 3) in the extracellular pathway (Zhang et al., 2018) (Fig. 4B). In hNKCC1, this network involves Y383 on TM3 that coordinates the $\mathrm{K}^{+}$ion as well as T499 on the unwound part of TM6. Highlighting the importance of these residues, $\mathrm{Tl}^{+}$influx in mammalian cells expressing $\mathrm{hNKCC} 1$ Y383F and Y383S mutants was impaired when compared to wild-type hNKCC1 (Fig. 4D), despite similar cell-surface expression of the mutants and wild-type NKCC1 (Fig. EV4 C-D).

On the opposite side of the binding pocket, Y533 on the bundle domain of TM7 interacts with A497 on TM6 as well as the $\mathrm{Cl}^{-}$ion through a water-mediated interaction (Fig. 4A). A substrate site coordination network has previously been described for the SLC6 transport family (Zhang et al., 2018). However, in contrast to the Y533 on TM7 in hNKCC1, the prokaryotic SLC6 homologues contain a conserved E290 ${ }^{\mathrm{LeuT}}$ on TM7 and eukaryotic SLC6 transporters contain a serine residue on TM7 that interacts with TM6 through a chloride ion (Coleman et al., 2016; Penmatsa et al., 2013). TM6 of SLC6 transporters interacts with the $\mathrm{Na}^{+}$ion at $\mathrm{Na} 1$ and the amine group of the amino acid substrate. Therefore, it seems that Y533 of hNKCC1 undertakes a role that is similar to both E290 ${ }^{\mathrm{LeuT}}$ (or a Cl${ }^{-}$site) and the Na1 sodium ion in SLC6 transporters. Supporting that this tyrosine residue is crucial for proper substrate translocation by NKCC1, replacing Y533 in hNKCC1 with a phenylalanine or glutamate residue abolishes $\mathrm{Tl}^{+}$influx in transfected mammalian cells (Fig. 4D).

\section{Second chloride binding site $(\mathrm{Cl} 2)$ is solvated}

Besides the $\mathrm{Cl}^{-}$ion bound at the main substrate site, NKCC1 transports a second $\mathrm{Cl}^{-}$ion accommodated at the $\mathrm{Cl} 2$ binding site further towards the cytoplasmic interface. The $\mathrm{Cl}^{-}$ion is coordinated by Y686 on TM10 and additionally, it interacts with the unwound part of TM6 (Fig. 5A). In contrast to the conservation of the $\mathrm{Na} 2$ binding site throughout most APC transporters, the two $\mathrm{Cl}^{-}$sites present in $\mathrm{hNKCC} 1$ are not found in any other APC transporters. Interestingly, the $\mathrm{Cl} 2$ site of hNKCC1 superimposes with the carboxylate side chain group of a strictly conserved glutamate residue on TM2 of SLC6 transporters (e.g. E136 ${ }^{\text {SERT }}$ and E62 $2^{\text {LeuT }}$ ), which is important for substrate transport and conformational changes (Chen et al, 2001; Korkhov et al, 2006; Sen et al, 2005; Sucic et al, 2002) (LeuT shown in Fig. 5B). Replacement of Y686 with a serine or glutamate residue substantially reduces transport activity of $\mathrm{NKCC} 1$ indicating that the residue is crucial for coordination of the chloride ion and maintaining the coupling network between the main binding pocket and distal parts of the transporter (Fig 5E). In $\mathrm{hNKCC} 1$, the $\mathrm{Cl}^{-}$ion bridges an interaction 
bioRxiv preprint doi: https://doi.org/10.1101/2021.11.11.468215; this version posted November 12, 2021. The copyright holder for this

between TM10 and TM6, whereas the conserved glutamate residue of SLC6 transporters connects TM2 with TM6 and interacts with another glutamate on TM10 (e.g. E508 ${ }^{\text {SERT }}$ and E419 ${ }^{\text {LeuT }}$ ). An interaction between TM2 and TM10 is also present in CCC transporters as N690 in hNKCC1 on TM10 interacts with two residues on TM2 (S337 and T334) (Fig. 5A and C). Importantly, and in contrast to the unsolvated sodium ion, the $\mathrm{Cl}^{-}$ion bound at $\mathrm{Cl} 2$ interacts with cytoplasmic water molecules (Fig. 5A).

\section{Substrate release}

The well-defined ion binding sites with solvation of the $\mathrm{Cl} 2$ site prompted us to investigate the substrate-bound complex by MD simulations. We performed twenty independent all-atom MD simulations of the transmembrane domain of our dimeric hNKCC1 embedded into a mixed lipid bilayer consisting of phosphatidylcholine (POPC)/phosphoethanolamine (POPE)/cholesterol at a ratio of 2:2:1, resulting in $8 \mu$ s accumulated trajectories. In agreement with observation of hydration of $\mathrm{Cl}^{-}$at the $\mathrm{Cl} 2$ site, the solvated $\mathrm{Cl}^{-}$ion was not stably bound and was able to leave its binding site for tens of ns and exchange for solvent $\mathrm{Cl}^{-}$ions. However, in contrast to the reversible release of $\mathrm{Cl}^{-}$, a subsequent release of the $\mathrm{Na}^{+}$ion after release of the $\mathrm{Cl}^{-}$ion from $\mathrm{Cl} 2$ marks a point of no return, and neither the $\mathrm{Cl}^{-}$or the $\mathrm{Na}^{+}$ions will rebind to their respective sites thereafter. Additionally, in some of our simulations we also observed that the $\mathrm{K}^{+}$substrate and the $\mathrm{Cl}^{-}$ion at Cl1 site left the binding sites almost at the same time, although complete substrate release events in the hNKCC1 dimer were rarely observed probably due to limited simulation time (200 ns for each) (Fig. 3E). Our atomistic MD simulations support a substrate release order in which $\mathrm{Cl}^{-}$at $\mathrm{Cl} 2$ site first releases, then $\mathrm{Na}^{+}$, and lastly $\mathrm{Cl}^{-}$at the $\mathrm{Cl1}$ site and $\mathrm{K}^{+}$in a cooperative manner.

\section{Discussion}

Structures of NKCC1 (Chew et al., 2019; Yang et al., 2020; Zhang et al., 2021) and KCC1-4 (Chi et al., 2021; Liu et al., 2019; Reid et al., 2020; Xie et al., 2020) indicate that the SLC12 family belongs to the APC superfamily with a LeuT-fold architecture (Fig. 1A). Here, we report a higher resolution structure of human NKCC1 in the substrate-bound form adopting an inward-oriented and occluded state. The $\mathrm{Na}^{+}$ion of NKCC1 binds at the conserved $\mathrm{Na} 2$ site, the $\mathrm{K}^{+}$and $\mathrm{Cl}^{-}$ion $(\mathrm{Cl} 1)$ bind at the general substrate binding pocket of the APC superfamily and the second $\mathrm{Cl}^{-}$ion $(\mathrm{Cl} 2)$ is found at the same location as a conserved glutamate residue of SLC6 transporters. 
bioRxiv preprint doi: https://doi.org/10.1101/2021.11.11.468215; this version posted November 12, 2021. The copyright holder for this preprint (which was not certified by peer review) is the author/funder, who has granted bioRxiv a license to display the preprint in perpetuity. It is made available under aCC-BY-NC 4.0 International license.

Our cryo-EM maps revealed the presence of interfacial lipids, which are also found in the zNKCC1 structure (Chew et al., 2019). These interfacial lipid molecules appear to be of great importance for stabilization of the transporter in its oligomeric state, as we experienced that hNKCC1 only retained its dimeric architecture when solubilized and purified in mild detergents like lauryl maltose neopentyl glycol (LMNG) and glyco-diosgenin (GDN), but not the de-lipidating n-dodecyl- $\beta$-Dmaltopyranoside (DDM). These findings are different from the dimeric KCC transporters that appear to be less lipid-dependent, with DDM routinely used for protein handling without disruption of the oligomeric state (Chi et al., 2021; Liu et al., 2019). This may be a result of the different oligomeric arrangements of the protomers in the transmembrane region of NKCC1 vs KCC structures. The dimers of sodium-independent CCCs rely on stronger interactions between the cytoplasmic domains, with weaker interactions between the transmembrane regions due to a larger distance between the two protomers (Fig. S1C) (Chew et al., 2019; Chi et al., 2021; Xie et al., 2020). Other transporters with low oligomeric stability, like LeuT from Aquifex aeolicus or NhaA from Escherichia coli, also contain lipids at their dimer interfaces that can easily be broken down by delipidating the protein or mutating residues within the lipid binding sites (Gupta et al, 2017). In addition to the crucial interfacial lipids, our cryo-EM map revealed presence of three cholesterol molecules per protomer, all localized at the extracellular part of the cotransporter, locking it in an inward-facing conformation. Interestingly, a similar regulatory role of cholesterol was suggested for the human serotonin transporter and the Drosophila melanogaster dopamine transporter (Coleman et al., 2016; Penmatsa et al., 2013), but these two transporters were stabilized in their outwardfacing conformations. Cholesterol depletion induced an inward-facing conformation of the serotonin transporter changing the substrate affinity, turnover rate and maximum transport velocity (Laursen et al, 2018). Whether cholesterol depletion can provide an experimental approach to generate structural information of $\mathrm{NKCC1}$ in an outward-orientated manner remains to be determined.

Although substrates of the CCC family are much smaller than substrates translocated by other APC transporters, the important coordination networks bridging between the scaffold and bundle domain remain strikingly similar. The Y383 residue on TM3 that is crucial for the LeuT transporter (Zhang et al., 2018) is conserved within the CCC family, with the exception of NCC where it is replaced with a histidine residue that likely undertakes the role of the missing $\mathrm{K}^{+}$substrate. Similar substitutions are observed in, for example, the sodium independent APC transporters where a positively charged basic residue on TM5 replaces the role of the $\mathrm{Na}^{+}$ion or in the case of 
bioRxiv preprint doi: https://doi.org/10.1101/2021.11.11.468215; this version posted November 12, 2021. The copyright holder for this preprint (which was not certified by peer review) is the author/funder, who has granted bioRxiv a license to display the preprint in perpetuity. It is made available under aCC-BY-NC 4.0 International license.

prokaryotic SLC6 transporters, where a $\mathrm{Cl}^{-}$ion present in eukaryotic transporters is substituted by a glutamate residue on TM7 (Coleman et al., 2016; Penmatsa et al., 2013). The coordination network is important for proper coupling between the main substrate and driving ion and therefore it is often conserved between APC transporters with drastically different substrates. The SLC11 family of divalent metal ions is an example of transporters that do not have this network, resulting in both coupled and uncoupled movements of either of the substrates (Mackenzie et al, 2006). A crystal structure of ScaDMT in complex with $\mathrm{Mn}^{2+}$ reveals that even though the architecture of the main binding pocket is strikingly similar to the binding pocket of $\mathrm{NKCC} 1$, substrate coordination is only maintained by the bundle domain (Ehrnstorfer et al., 2014).

The $\mathrm{Na}^{+}$binding site is highly conserved throughout sodium-dependent APC transporters (Fig. S5A-C) (Faham et al., 2008; Khafizov et al, 2012; Krishnamurthy et al, 2009; Malinauskaite et al., 2014; Penmatsa et al., 2013; Perez et al, 2012; Weyand et al, 2008; Yamashita et al., 2005). The crucial role of the $\mathrm{Na} 2$ site seems also to be retained in many sodium-independent transporters adopting the LeuT-fold (Fig. S5D-F). Crystal structures revealed that these transporters often contain a charged amine group at this location that undertakes the role of the $\mathrm{Na}^{+}$, creating a link between TM1 and TM8 (e.g. R262 of CaiT (Kalayil et al, 2013), K158 in ApcT (Shaffer et al, 2009) and K154 in BasC (Errasti-Murugarren et al, 2019) ). Contrastingly, KCC transporters do not contain any basic residues near the $\mathrm{Na} 2$ site, thereby suggesting a different mechanism than in other sodium-independent APC transporters. The lack of $\mathrm{Na}^{+}$coupling is reflected in the transport directionality of $\mathrm{KCC}$ transporters that translocate a $\mathrm{K}^{+}$and $\mathrm{Cl}^{-}$ion from the cytoplasm to the extracellular space (Fig. 2B and S6A). Structure superposition of hNKCC1 and the hKCC1 revealed a slight 2-3 $\AA$ displacement of TM8 that might impact $\mathrm{Cl}^{-}$coupling at the $\mathrm{Cl} 2$ site, as $\mathrm{KCC}$ transporters only transport one $\mathrm{K}^{+}$and one $\mathrm{Cl}^{-}$(Fig. S7A and B) (Liu et al., 2019). Interestingly, in close proximity to the $\mathrm{Na} 2$ site, $\mathrm{L} 297^{\mathrm{hNKCC} 1}$ is substituted with $\mathrm{Q} 130^{\mathrm{hKCC} 1}$ in $\mathrm{KCC} 1$ on $\mathrm{TM} 1$, and L616 ${ }^{\mathrm{hNKCC} 1}$ is substituted by $\mathrm{Q} 521^{\mathrm{hKCC} 1}$ on TM8. Together with $\mathrm{N} 131^{\mathrm{hKCC} 1}$ these residues could create a flexible hydrogen bond network linking TM1 and TM8 in the outward-facing conformation of KCCs that stabilizes the interface between the bundle and scaffold domain (Fig. S6B). These substitutions are not present in any of the sodium-dependent CCC transporters (Fig. S6C).

The $\mathrm{Cl} 2$ binding site of $\mathrm{hNKCC} 1$ and other CCC's is placed towards the cytoplasm and bridges between TM10 and the unwound part of TM6, in a similar way as the crucial glutamate residue on TM2 does in SLC6 transporters. For SLC6 type transporters such as LeuT and SERT, the 
bioRxiv preprint doi: https://doi.org/10.1101/2021.11.11.468215; this version posted November 12, 2021. The copyright holder for this preprint (which was not certified by peer review) is the author/funder, who has granted bioRxiv a license to display the preprint in perpetuity. It is made available under aCC-BY-NC 4.0 International license.

interaction between $\mathrm{E} 62^{\mathrm{LeuT}}$ or the equivalent E136 ${ }^{\mathrm{SERT}}$ and the unwound junction of TM6 is maintained throughout all the known states, highlighting the importance of this interaction (Focht $e t$ al, 2021). It seems that the $\mathrm{Cl}^{-}$ion together with $\mathrm{Y}_{686}{ }^{\mathrm{hNKCC1}}$ replaces the role of E62 ${ }^{\mathrm{LeuT}}$ and allows for transport translocation. The coordination network between TM2-TM10- $\mathrm{Cl}^{-}$-TM6 in NKCC1 therefore appears to play the same role as the TM10-TM2-water-TM6 network within SLC6 transporters connecting the main binding site to distal rearrangements of the transporter. The close interactions between TM10-TM2 and TM6 mediated through a glutamate-water network (SLC6) or $\mathrm{a} \mathrm{Cl}^{-}$ion (SLC12) cannot be found in other APC families. Interestingly, structural analysis revealed that other transporters use different interaction types in order to maintain the interactions between these helices. For vSGLT (SLC5) a phenylalanine on TM10 and a second phenylalanine on the unwound part of TM6 make $\pi-\pi$ interactions. Additionally, TM10 and TM2 contain a number of aromatic residues $\left(\mathrm{F} 447^{\text {vSGLT }}\right.$, Y $101^{\text {vSGLT }}$ and $\mathrm{F} 102^{\text {vSGLT }}$ ) potentially interacting hydrophobically and bringing these two helices in close proximity (Fig. S7 A). In a similar manner the GkApcT (SLC7) transporter contains two aromatic residues maintaining the interaction between TM10 and TM6, whereas the TM2-TM10 interaction is maintained by a salt bridge (Fig. S7 B).

Both $\mathrm{Cl}^{-}$sites of $\mathrm{NKCC} 1$ are conserved in $\mathrm{KCC}$ transporters, with published $\mathrm{KCC}$ structures having both sites occupied (Fig. 5D) (Liu et al., 2019) despite KCCs transporting only one $\mathrm{Cl}^{-}$ion. Interestingly, mutagenesis of residues coordinating either of the two $\mathrm{Cl}^{-}$ions impair transport, suggesting that both $\mathrm{Cl}^{-}$sites are required (Liu et al., 2019). This indicates that the $\mathrm{Cl} 2$ site in SLC12 transporters also displays integral, functional properties similar to the conserved glutamate of TM2 in SLC6 transporters (e.g. Glu136 ${ }^{\text {SERT }}$ ). We speculate that this site is adapted for a $\mathrm{Cl}^{-}$ sensory function in $\mathrm{KCC}$ transporters, which activates $\mathrm{Cl}^{-}$efflux at high cytoplasmic concentrations of chloride and oppositely blocks efflux at low cytoplasmic $\mathrm{Cl}^{-}$concentrations.

Structural characterization of hNKCC1 allowed us to generate a homology model of the transmembrane part of hNCC and analyze its ion coupling mechanisms and binding site specificity. As mentioned, NCC contains a histidine residue $\left(\mathrm{H} 234^{\mathrm{NCC}}\right)$ instead of the crucial tyrosine on TM3 of NKCC and $\mathrm{KCC}$ that coordinates the $\mathrm{K}^{+}$ion (Fig. 4C). In its protonated, positively charged state, the histidine residue could replace the $\mathrm{K}^{+}$ion transported by other $\mathrm{CCC}$ transporters in a similar manner as a positively charged arginine or lysine residue performs the function of the $\mathrm{Na}^{+}$ion at the $\mathrm{Na} 2$ site in sodium-independent APC transporters (Fig. S5D-F). Moreover, the central localization on TM3 would still allow the histidine residue to participate in the important coordination network 
bioRxiv preprint doi: https://doi.org/10.1101/2021.11.11.468215; this version posted November 12, 2021. The copyright holder for this

within the main binding pocket and maintain the high substrate selectivity and coupling. As expected, the $\mathrm{Na} 2$ binding site in NCC is also fully conserved compared to NKCC1 and NKCC2 (Fig. 2D), because NCC also uses $\mathrm{Na}^{+}$coupling to drive $\mathrm{Cl}^{-}$movement from the extracellular space to the cytoplasm. Surprisingly, however, sequence alignment and the homology model indicate that both $\mathrm{Cl}^{-}$sites are again conserved (Fig. 5D). It is possible, that two $\mathrm{Cl}^{-}$ions might be required to bind in order to allow the transporter to go through different conformations or $\mathrm{Cl}^{-}$may have an inhibitory effect at high cytoplasmic $\mathrm{Cl}^{-}$concentrations. Interestingly, earlier studies of NKCC1 have provided evidence that the two $\mathrm{Cl}^{-}$binding sites are nonequivalent and exhibit different $\mathrm{Cl}^{-}$ affinities: a low $\mathrm{Cl}^{-}$affinity site was identified closer to the cytoplasm and in near proximity of the $\mathrm{Na}^{+}$site (corresponding to the $\mathrm{Cl} 2$ site in our structure: $\mathrm{K}_{\mathrm{m}}=55.3 \mathrm{mM}$ ) and a high $\mathrm{Cl}^{-}$affinity site found closer to the extracellular environment and in close proximity to the $\mathrm{K}^{+}$site (corresponding to the $\mathrm{Cl1}$ site in our structure: $\mathrm{Km}=5.1 \mathrm{mM}$ ). In addition to the significant difference in $\mathrm{Cl}^{-}$affinity between the two sites, it was also shown that the binding characteristics of the two sites are very different, as $\mathrm{Cl} 2$ only was able to bind and transport $\mathrm{Cl}^{-}$ions, whereas $\mathrm{Cl} 1$ could also bind and transport $\mathrm{NO}_{3}{ }^{-}$and $\mathrm{SCN}^{-}$in addition to $\mathrm{Cl}^{-}$(Brown \& Murer, 1985; Kinne et al, 1986; Russell, 2000; Turner \& George, 1988). We speculate, that if the two predicted $\mathrm{Cl}^{-}$sites in $\mathrm{NCC}$ exhibit similar properties as NKCC1, one of the sites might act as a substrate site, whereas the second site with lower $\mathrm{Cl}^{-}$affinity could function as a regulatory site and only allow transport when the cytoplasmic $\mathrm{Cl}^{-}$concentration is low.

For the SLC6 transporters the $\mathrm{Na}^{+}$ion is released first to the intracellular environment followed by the remaining substrates (Li et al, 2019; Malinauskaite et al., 2014). Contrastingly, our highresolution cryo-EM map of hNKCC1 demonstrated solvation of the $\mathrm{Cl}^{-}$ion bound at the $\mathrm{Cl} 2$ site, but not of the $\mathrm{Na}^{+}$ion. Independently, our MD simulations of NKCC1 revealed that the $\mathrm{Cl}^{-}$ion is the first to be released, but its release is not a determining step in transport as it is observed to bind reversibly. However, when the $\mathrm{Na}^{+}$ion leaves as a second event in NKCC1 dynamics, none of the released ions rebind, and later the $\mathrm{K}^{+}$and $\mathrm{Cl}^{-}$ion at the main substrate cavity leave and the transporter is ready for return to the outward-open conformation (Fig. 3E). We also identified a possible $\mathrm{Na}^{+}$release pathway along TM5 (Fig. 2E) lined with two glutamate residues at the opening of the cavity that attract and escort the $\mathrm{Na}^{+}$ion to the cytoplasmic environment. Previous reports established that the deactivating phosphorylation of the C-terminus of sodium-independent KCC transporters leads to autoinhibition by blockage of pathway 1 and partially pathway 2 by a 26 residues long part of the flexible $\mathrm{N}$-terminus (Xie et al., 2020). Alternatively, the activating 
bioRxiv preprint doi: https://doi.org/10.1101/2021.11.11.468215; this version posted November 12, 2021. The copyright holder for this

phosphorylation of NKCC1 was hypothesized to interact with the intracellular cytoplasmic domain of the transporter, disrupting a condense, inactive state (Monette \& Forbush, 2012; Zhang et al., 2021). We speculate that the lack of TM5 unwinding along pathway 1 together with absence of helix-breaking motifs in the intracellular part of TM5 (Fig. S4), might be replaced with a more pronounced movement of TM1a during substrate release due to activating phosphorylation of the N-terminus.

Interestingly, there is no consensus in the field about the potential substrate release mechanism of CCC transporters. Two different substrate binding and release models were proposed previously (Delpire \& Gagnon, 2011; Lytle et al, 1998). In the so-called 'glide-symmetry' model, the outwardfacing conformation of NKCC1 first binds the $\mathrm{Na}^{+}$ion, then the $\mathrm{Cl}^{-}$at the $\mathrm{Cl} 2$ site, followed by $\mathrm{K}^{+}$ and $\mathrm{Cl}^{-}$from $\mathrm{Cl} 1$ site. Then in the inward-facing state, the substrates are released in the same order (Lytle et al., 1998). The 'steady state' model, on the other side, suggests that the outward-open state first binds $\mathrm{Cl}^{-}$at the $\mathrm{Cl} 2$ site, then the $\mathrm{Na}^{+}$ion, followed by the second $\mathrm{Cl}^{-}$ion at the $\mathrm{Cl} 1$ site and the $\mathrm{K}^{+}$ion, whereas the substrates are released a reverse order to the cytoplasmic environment (Delpire \& Gagnon, 2011). The substrate release mechanism proposed in our work does not fit any of the two hypothesized substrate release mechanisms. Intracellular release of $\mathrm{Cl}^{-}$from $\mathrm{Cl} 2$ prior to the $\mathrm{Na}^{+}$ion was independently observed, first by visualization of the intracellular solvation network of hNKCC1 leading to hydration of the $\mathrm{Cl}^{-}$but not the $\mathrm{Na}^{+}$ion, and secondly by use of MD simulations where the $\mathrm{Cl}^{-}$ion was shown to leave the transporter before the $\mathrm{Na}^{+}$ion. We speculate that the observed reversibility of $\mathrm{Cl}^{-}$binding and unbinding at $\mathrm{Cl} 2$ found in our MD simulations might have prevented proper evaluation of the substrate release order in the previously published studies. Interestingly, if the 'steady state' model assumed glide-symmetry instead of mirrorsymmetry, as found for other LeuT-fold transporters, the mechanism would fit well with our findings. However, we cannot exclude that our release model might have been impacted by limitations of the cryo-EM approach applied. For example, extraction of the transporter from the native membrane followed by detergent-based protein purification changes the system significantly when compared to the natural environment of $\mathrm{NKCC1}$ in cells. Furthermore, a lack of other cell components, protein interaction partners, alterations in fluid composition (needed to stabilize the isolated protein) or a lack of membrane potential might have a pronounced effect on the transport dynamics. Therefore, further structures of the CCCs in different conformational states are still needed to properly understand the substrate binding and release events. 
bioRxiv preprint doi: https://doi.org/10.1101/2021.11.11.468215; this version posted November 12, 2021. The copyright holder for this

In conclusion, SLC12 transporters are of great importance for proper functioning of all organisms ranging from humans and vertebrate animals through plants (Colmenero-Flores et al, 2007) and fungi to insects, worms and cyanobacteria (Hartmann et al, 2014). Insight into the threedimensional structure and mechanistic details of substrate binding, translocation and release might lead to better understanding of the role of these transporters in normal physiology and their pathophysiological roles. Our $2.6 \AA$ structure of occluded and inward-facing hNKCC1 provides not only a direct insight into substrate accommodation, but it is the first structure of a SLC12 transporter with a high enough resolution to resolve the intracellular water networks and reveal solvation of $\mathrm{Cl}^{-}$at $\mathrm{Cl} 2$ but not $\mathrm{Na}^{+}$(Fig. 2A and 4A). By a combination of structural studies and MD simulations we show that the $\mathrm{Cl}^{-}$ion is released before the $\mathrm{Na}^{+}$ion and we also identify a potential intracellular release pathway of $\mathrm{Na}^{+}$lined by two glutamate residues crucial for attracting and escorting the cation out of the transporter. Finally, we identify the $\mathrm{Cl} 2$ site as a potential sensory and stabilizing site of the transporter, where the $\mathrm{Cl}^{-}$has the same role as a strictly conserved glutamate residue in SLC6 transporters, maintaining the coupling network between the unwound part of TM6 and distal parts of the transporter to enable conformational transitions of NKCC1. In general, insight into the ion coupling networks and the transport mechanism of the CCCs can improve our understanding of not only the physiological roles of the transporter and other SLC12 transporters, but also help with determination of specific buffer composition, mutations and/or nanobodies necessary for structural studies focusing on different conformational states of the CCCs, e.g. in a similar manner as earlier done for LeuT (Focht et al., 2021; Gotfryd et al., 2020; Krishnamurthy \& Gouaux, 2012; Malinauskaite et al., 2016). In addition, knowledge of the exact molecular contributions of significant residues during the transport cycle can further help with rational drug design, thereby leading to safer and more target-specific pharmaceuticals, in contrary to the less-specific loop diuretics used nowadays to treat hypertension and edema (e.g. bumetanide inhibits NKCC1, NKCC2 as well as KCC1-4) (Gillen et al, 1996; Holtzman et al, 1998; Race et al, 1999).

\section{Materials and methods}

\section{Reagents.}

All chemicals were obtained from Sigma, unless stated otherwise.

\section{Expression and purification of the human NKCC1.}


bioRxiv preprint doi: https://doi.org/10.1101/2021.11.11.468215; this version posted November 12, 2021. The copyright holder for this preprint (which was not certified by peer review) is the author/funder, who has granted bioRxiv a license to display the preprint in perpetuity. It is made available under aCC-BY-NC 4.0 International license.

The full-length human NKCC1 with a N-terminal 8xHis-TwinStrep-GFP-tag3Cprotease_cleavage_site was expressed in HEK293 $\mathrm{GnTl}^{-}$(ATCC) cells by use of the BacMam system as described earlier (Goehring et al, 2014). HEK293 $\mathrm{GnTl}^{-}$cells were grown to a density of $3 \times 10^{6}$ cells $/ \mathrm{mL}$ at $37^{\circ} \mathrm{C}$ and $5 \% \mathrm{CO}_{2}$ on an orbital shaker at $120 \mathrm{rpm}$. The cells were then transduced with the P3 NKCC1 BacMam virus to a MOI of 3 and the cells were further incubated in the incubator. $24 \mathrm{~h}$ post transduction $10 \mathrm{mM}$ sodium butyrate was added to the cells and the temperature was lowered to $30^{\circ} \mathrm{C}$ with $5 \% \mathrm{CO}_{2}$ while shaking $(120 \mathrm{rpm})$. After $48 \mathrm{~h}$ the cells were harvested by centrifugation at $6,200 \mathrm{x}$ g at $4^{\circ} \mathrm{C}$. The cell pellets were stored at $-80^{\circ} \mathrm{C}$.

The frozen cell pellet was thawed and resuspended in a buffer composed of $200 \mathrm{mM} \mathrm{NaCl}, 200 \mathrm{mM}$ $\mathrm{KCl}, 20 \mathrm{mM}$ Tris- $\mathrm{HCl} \mathrm{pH} 8.0,10 \%$ (v/v) glycerol and $0.07 \mathrm{mM}$ bumetanide. The cells lysed by sonication and centrifugated for $20 \mathrm{~min}$ at $20,000 \mathrm{x}$ g at $4^{\circ} \mathrm{C}$. The collected supernatant was further centrifugated at $163,000 \times \mathrm{g}$ for 3 hours at $4^{\circ} \mathrm{C}$ and the pellet was thereafter resuspended in the same buffer with a ratio of $10 \mathrm{~mL}$ buffer per $1 \mathrm{~g}$ of wet pellet. $1 \%$ lauryl maltose neopentyl glycol (LMNG, Anatrace) and $0.1 \%$ cholesteryl hemisuccinate (CHS, Anatrace) was added and the membrane proteins were solubilized overnight at $4^{\circ} \mathrm{C}$. The mixture was then centrifugated at 14000 $\mathrm{x} g$ for $30 \mathrm{~min}$, the insoluble fraction was discarded and the supernatant was incubated with StrepTactin resin for $3 \mathrm{~h}$. The resin was washed with 10 column volumes washing buffer containing $0.01 \%$ LMNG, $0.001 \%$ CHS, 200mM NaCl, 200mM KCl, 20mM Tris-HCl pH 8.0, 10\% (v/v) glycerol and $0.07 \mathrm{mM}$ bumetanide. The hNKCC1 protein was eluted with wash buffer supplemented with $5 \mathrm{mM}$ desthiobiotin. The sample was then cleaved overnight with $3 \mathrm{C}$ protease and concentrated to $3 \mathrm{mg} / \mathrm{mL}$. The protein was further purified by gel filtration (Superose 6 3.2/300) on an Äkta Purifier system equilibrated in a buffer composed of $0.01 \%$ glycol-diosgenin (GDN, Anatrace), $200 \mathrm{mM} \mathrm{NaCl}, 200 \mathrm{mM} \mathrm{KCl}, 20 \mathrm{mM}$ Tris- $\mathrm{HCl} \mathrm{pH} 8.0$ and $0.07 \mathrm{mM}$ bumetanide. Peak fractions were collected and concentrated to $0.9-1.5 \mathrm{mg} / \mathrm{mL}$ for cryo-EM studies.

\section{Thallium ion $\left(\mathrm{Tl}^{+}\right)$flux transport assay}

The NKCC1 mutant constructs were designed in the same way as the wt NKCC1 construct used for structure determination. The mutants were prepared by GenScript. Activity levels of the wild-type NKCC1 transporter and NKCC1 mutants were determined by use of the thallium ion flux transport assay. The construct with a N-terminal 8xHis-TwinStrep-GFP-tag were expressed in GripTite HEK293 MSR cells (Thermo Fisher) in black 96 well plates with transparent bottoms. The cells 
bioRxiv preprint doi: https://doi.org/10.1101/2021.11.11.468215; this version posted November 12, 2021. The copyright holder for this

were maintained in DMEM GlutaMAX medium (Gibco) with addition of 10\% FBS and 1x nonessential amino acid (NEAA) cell culture supplement. 50,000 cells were seeded out per well and the cells were incubated for $24 \mathrm{~h}$ at $37^{\circ}$ with $8 \% \mathrm{CO}_{2}$. On the day of transfection, $3 \mu \mathrm{L}$ Lipofectamine 3000 (Invitrogen) was mixed with $47 \mu \mathrm{L}$ Opti-Mem medium (Gibco). Separately, 1000ng DNA was diluted in $36 \mu \mathrm{L}$ Opti-MEM medium with addition of $4 \mu \mathrm{L}$ P3000 reagent (Invitrogen) and thereafter, the Lipofectamine 3000 solution was mixed with the DNA solution. After 15 min. incubation, $10 \mu \mathrm{L}$ of the mixture was added to each of the wells. After 5-6 hours, $100 \mu \mathrm{L}$ DMEM medium, 1x NEAA and 30\% FBS was added to each well. The activity assay was performed $72 \mathrm{~h}$ post transfection of the cells.

On the day of the experiment, the DMEM medium was exchanged for $80 \mu \mathrm{L}$ loading buffer containing probenecid, PowerLoad and FluxOR II Reagent from the FluxOR II Red Potassium Ion Channel Assay kit (Thermo Fisher Scientific) and a low chloride buffer (15 mM Na-HEPES pH 7.4, $135 \mathrm{mM}$ Na-gluconate, $1 \mathrm{mM} \mathrm{MgCl}{ }_{2}-6 \mathrm{H}_{2} \mathrm{O}, 1 \mathrm{mM} \mathrm{Na}_{2} \mathrm{SO}_{4}$ and $\left.1 \mathrm{mM} \mathrm{CaCl}_{2}-2 \mathrm{H}_{2} \mathrm{O}\right)$. The cells were incubated with the loading buffer for $1 \mathrm{~h}$ at room temperature and thereafter, they were washed once with the low chloride buffer with addition of probenecid, followed by addition of $80 \mu \mathrm{L}$ buffer to each well.

The assay was performed using the ENSPIRE 2300 kinetic dispense microplate reader (PerkinElmer). First, GFP fluorescence was measured for later normalization (excitation at $480 \mathrm{~nm}$, emission at $510 \mathrm{~nm}, 100$ flashes, 3 repeats, $0.1 \mathrm{~s}$ ). After $5 \mathrm{~s}$ of baseline recording (10 repeats) the transport assay was initiated by addition of $20 \mu \mathrm{L}$ stimulation buffer containing low chloride buffer, $135 \mathrm{mM} \mathrm{NaCl}$, and $5 \mathrm{mM}$ thallium sulfate with or without $165 \mu \mathrm{M}$ bumetanide (final concentrations of $27 \mathrm{mM} \mathrm{NaCl}, 1 \mathrm{mM}$ thallium sulfate and $33 \mu \mathrm{M}$ of bumetanide). The excitation wavelength was set to $565 \mathrm{~nm}$ and the emission wavelength was set to $583 \mathrm{~nm}$. The plate was read every $0.5 \mathrm{~s}$ for 80 repeats $(40 \mathrm{~s})$.

\section{Biotinylation assay}

Cell surface protein biotinylation was performed to estimate the plasma membrane expression of various NKCC1 mutants relative to the wild-type transporter. The N-terminal 8xHis-TwinStrepGFP-tagged NKCC1 constructs were expressed in GripTite HEK293 MSR cells (Thermo Fisher) in 24 well plates. The transfection of cells was performed in the same was as done for the $\mathrm{Tl}^{+}$uptake 
bioRxiv preprint doi: https://doi.org/10.1101/2021.11.11.468215; this version posted November 12, 2021. The copyright holder for this

assay, but the amounts were scaled up. The biotinylation assay was performed $72 \mathrm{~h}$ after transfection of the cells.

The cells were washed in basic buffer $(135 \mathrm{mM} \mathrm{NaCl}, 5 \mathrm{mM} \mathrm{KCl}, 1 \mathrm{mM} \mathrm{CaCl2}-2 \mathrm{H} 20,1 \mathrm{mM}$ MgCl2-6H20, $1 \mathrm{mM}$ Na2HPO4-2H20, $1 \mathrm{mM}$ Na2SO4, $15 \mathrm{mM}$ Sodium HEPES pH 7.4) and incubated in the low chloride buffer (same as in uptake assay) for $1 \mathrm{~h}$ at $18-24^{\circ} \mathrm{C}$. Thereafter, the cells were placed on ice and washed with ice-cold PBS-CM buffer (PBS pH 7.5 with addition of 1 $\mathrm{mM} \mathrm{CaCl} 2,0.1 \mathrm{mM} \mathrm{MgCl}_{2}$ ), followed by the biotinylation buffer (10 $\mathrm{mM}$ triethanolamine, $2 \mathrm{mM}$ $\mathrm{CaCl}_{2}, 125 \mathrm{mM} \mathrm{NaCl}$ ). The cells were incubated in the biotinylation buffer with addition of 1 $\mathrm{mg} / \mathrm{mL}$ of sulfosuccinimidyl 2-(biotin-amido)-ethyl-1,3-dithiopropionate (EZ-link Sulfo-NHS-SSbiotin, Pierce) for $30 \mathrm{~min}$ at $4^{\circ} \mathrm{C}$. After the incubation period, the cells were washed with ice-cold quenching buffer (50 mM Tris-HCl in PBS-CM buffer), followed by the PBS-CM buffer. The cells were incubated in lysis buffer $(20 \mathrm{mM}$ Tris- $\mathrm{HCl} \mathrm{pH}$ 8.0, $5 \mathrm{mM}$ EDTA, $150 \mathrm{mM} \mathrm{NaCl}, 1 \%$ Triton $\mathrm{X}-100,0.2 \% \mathrm{BSA}$ and Halt ${ }^{\circledR}$ protease inhibitors) for $30 \mathrm{~min}$ on ice, followed by probe sonication. Thereafter, the homogenates were centrifugated at $10,000 \mathrm{xg}$ for 5 minutes at $4^{\circ} \mathrm{C}$. One fraction was retained for total NKCC1 protein abundance estimation and the remainder was incubated for $1 \mathrm{~h}$ with Neutravadin resin at room temperature under rotation. The resin was washed four times with PBS containing protease inhibitors and the bound protein was eluted by addition of SDS-PAGE sample buffer to the resin. Western blotting was performed using standard methods using antiNKCC1 antibody.

\section{Cryo-EM sample preparation and data collection}

For preparation of grids, freshly purified hNKCC1 protein was used. Grids used were UltrAuFoil 1.2/1.3-300, glow-discharged in residual atmospheric air for $45 \mathrm{sec}$ at $15 \mathrm{~mA}$ in a GloQube (Quorum). A $3 \mathrm{uL}$ drop was applied to the gold foil side of the grid and blotted in a Vitrobot Mark IV (ThermoFisher Scientific) using a blot force of 0 and blot time of 3-4 seconds before plungefreezing into liquid ethane cooled by liquid nitrogen. Micrograph data was collected on a Titan Krios G3i microscope (ThermoFisher Scientific) operated at $300 \mathrm{KeV}$ equipped with a BioQuantum energy filter (energy slit width $20 \mathrm{eV}$ ) and K3 camera (Gatan). For data sets 1 and 2 (collected at the Krios2 microscope, EMBION facility, Aarhus University) a nominal magnification of 165,000x was used, resulting in a physical pixel size of $0.507 \AA^{2} /$ px with a total dose of $40.12 \mathrm{e}^{-} / \AA^{2}$ for data set 1 and a total dose of $39.78 \mathrm{e}^{-} / \AA^{2}$ for data set 2 . For both data sets, movies were fractionated into 
bioRxiv preprint doi: https://doi.org/10.1101/2021.11.11.468215; this version posted November 12, 2021. The copyright holder for this

43 frames. The defocus range was set to 0.6-1.6 micron. For dataset 3 (collected on Titan Krios at eBIC, Oxford, UK), a nominal magnification of 130,000x was used, resulting in a physical pixel size of $0.83 \AA^{2} / \mathrm{px}$, with movies saved in super-resolution pixel size of $0.415 \AA^{2} / \mathrm{px}$. A total dose of $60.438 \mathrm{e}^{-} / \AA^{2}$ per movie was spread across 40 frames. The defocus range was set to $0.5-2.4$ micron.

\section{Cryo-EM data processing}

Datasets 1 and 2 were processed exclusively in RELION-3.1 (Scheres, 2012) (Fig. EV1), whereas dataset 3 was processed primarily in RELION-3.1 with some classifications performed using the heterogeneous refinement in cryosparc3 (Punjani et al., 2017) (Fig. EV2). For all data sets, movies were motion corrected using RELION's own MotionCorr implementation and CTFFind4 (Rohou \& Grigorieff, 2015) used for determination of CTF parameters. Only micrographs with CTF fit resolution better than $4 \AA$ were used onwards. Initial particle picking was done using RELION's LoG-picker on a small, random subset of micrographs in data set 1. Picked particles were extracted with a 512-pixel box, downsampled to 128 pixels, and subjected to 2D classification. Clear junk particles were discarded, and the remainder of particles were used in 3D auto-refinement with the zNKCC1 reconstruction (EMD-0473) as initial reference, lowpass filtered to $30 \AA$ resolution. The resulting $3 \mathrm{D}$ reconstruction was used in $2 \mathrm{D}$ classification without image alignment, and the best $2 \mathrm{D}$ class averages were used for template-based particle picking on all micrographs for all three data sets. Particle images were extracted in a 480-pixel box, downsampled to 128 pixels, and 2D classified using fast subsets and skipping CTF until first peak. Clear junk classes were discarded, and the remainder raw particle set was subjected to 3D classification using fast subsets and 8 classes for data set 1 and 10 classes for data set 2. Particles from the 3D classes displaying features of an intact detergent micelle were selected and run through 3D auto-refinement followed by 2D classification without image alignment. Again, clear junk was discarded, and the remainder particles were re-extracted with downsampling to a 240-pixel box (1.014 $\left.\AA^{2} / \mathrm{px}\right)$. Particles were again subjected to 3D classification now without fast subsets, using 8 and 6 classes for data set 1 and 2, respectively. The 3D classes displaying clear density features of transmembrane helices were selected and subjected to unmasked 3D auto-refinement. The resulting consensus reconstructions were deemed of good enough quality to proceed with Bayesian polishing, followed by 3D autorefinement with a mask around the transmembrane domains and application of $\mathrm{C} 2$ symmetry. The resulting masked $3 \mathrm{D}$ reconstructions were resolved better than $3 \AA$, which upon merging of the particles from data sets 1 and 2 were 3D auto-refined to a high-quality reconstruction of $2.6 \AA$ 
bioRxiv preprint doi: https://doi.org/10.1101/2021.11.11.468215; this version posted November 12, 2021. The copyright holder for this

resolution. For data set 3 , subsequent to $2 \mathrm{D}$ classification and the first $3 \mathrm{D}$ classification in RELION-3.1, the particle image stack was further cleaned by discarding junk classes from a 2D classification job without image alignment. The resulting stack of 595,171 particle images were reextracted in a 384-pixel box without downsampling before loaded into Cryosparc3 and further classified by ab-initio reconstruction and heterogenous refinement using three classes. A single class of particles showed high-resolution features for the transmembrane helices, with the cytoplasmic domains being almost impossible to see. This new stack of particle images was taken back into RELION-3.1, cleaned yet again using 2D classification without image alignment, and particle image re-extracted in a 294-pixel box with downsampling to 240 pixels $\left(1.016 \AA^{2} / p x\right)$. The now clean stack of particle images was subjected to 3D auto-refinement, Bayesian polishing and 3D auto-refinement again using a mask around the transmembrane domains and applying $\mathrm{C} 2$ symmetry. The resulting reconstruction showed high-quality density features resolved slightly better than $3 \AA$. Using CTF refinement for anisotropic magnification to account for the small discrepancy in pixel size, the data set 3 particles were merged with the already combined particle data from data set 1 and 2, to give a final 3D-refined reconstruction of 2.55- $\AA$ average resolution for the transmembrane domains (Fig. EV2A). Local resolution estimation was done using RELION's own implementation (Fig. EV2B).

\section{Model building and refinement}

The transmembrane domain of hNKCC1 was built in Coot (Emsley et al, 2010), guided by the Danio rerio NKCC1 structure (PDB entry: 6NPL) (Chew et al., 2019). The refinement was done by use of Real Space Refinement in Phenix (Afonine et al, 2018) and manual corrections of the structure were performed in Coot. Validation of the structure was done in MolProbity (Williams et al, 2018).

\section{System setup for molecular dynamics simulations}

A model of hNKCC1 was constructed using the Cryo-EM structure of the transmembrane domain of hNKCC1 in complex with its substrates, one $\mathrm{Na}^{+}$, one $\mathrm{K}^{+}$and two $\mathrm{Cl}^{-}$ions. In addition, four CHS molecules identified in the Cryo-EM structure were replaced by the cholesterol molecules. The model was subsequently embedded into a flat, mixed lipid bilayer consisting of $\mathrm{POPC} / \mathrm{POPE} / \mathrm{cholesterol}$ at a 2:2:1 ratio, and solvated in a cubic water box containing $0.1 \mathrm{M} \mathrm{NaCl}$ and $0.1 \mathrm{M} \mathrm{KCl}$. The size of the box was $13.1 \mathrm{~nm}, 13.1 \mathrm{~nm}$ and $10.2 \mathrm{~nm}$ in the $\mathrm{x}, \mathrm{y}$ and $\mathrm{z}$ dimension, 
bioRxiv preprint doi: https://doi.org/10.1101/2021.11.11.468215; this version posted November 12, 2021. The copyright holder for this

respectively, resulting in $\sim 180,000$ atoms in total. The CHARMM36m force field was used for the protein and the CHARMM36 lipid force field was used for all lipid molecules.

In the MD simulations, the temperature was kept constant at $310 \mathrm{~K}$ using a Nose-Hoover thermostate with a 1 ps coupling constant, and the pressure at 1.0 bar using the Parrinello-Rahman barostat with a 5 ps time coupling constant. A cutoff of $1.2 \mathrm{~nm}$ was applied for the van der Waals interactions using a switch function starting at $1.0 \mathrm{~nm}$. The cutoff for the short-range electrostatic interactions was also at $1.2 \mathrm{~nm}$ and the long-range electrostatic interactions were calculated by means of the particle mesh Ewald decomposition algorithm with a $0.12 \mathrm{~nm}$ mesh spacing. A reciprocal grid of $112 \times 112 \times 96$ cells was used with 4th order B-spline interpolation. All MD simulations were performed using Gromacs2019.6 (Abraham et al, 2015). Twenty independent simulations (200 ns for each) were performed for the hNKCC1 model, so resulting in $8 \mu \mathrm{s}$ simulations (20 runs x $200 \mathrm{~ns} \times 2$ monomers) in total.

\section{Acknowledgements}

The authors are grateful to technical assistance by Tina Drejer, Tetyana Klymchuk, Anna Marie Nielsen, Bente Andersen and Anne Lillevang. We want to thank Thomas Boesen, Andreas Bøggild and Taner Drace from the cryo-EM facility at Aarhus University for assistance with grid screening and numerous overnight data collections. We are thankful to Milena Timcenko, Jeppe Achton Nielsen, Søren Kirk Amstrup and Jonathan Juhl for help with data processing and fruitful discussions about cryo-EM. We want to acknowledge Qi Wu for performing MS on the purified hNKCC1 sample in order to assure that sample of the expressed and purified hNKCC1 construct was correct.

We acknowledge Diamond Light Source for access and support of the cryo-EM facilities at the UK's National Electron Bio-Imaging Centre (eBIC) under proposal AP27 funded by the Wellcome Trust, MRC and BBRSC.

Work on the project was supported by a PhD fellowship from the Lundbeck Foundation to CN (2015-3225), the Leducq Foundation (17CVD05), the Novo Nordisk Foundation (NNF21OC0067647, NNF17OC0029724, NNF19OC0058439) and the Independent Research Fund Denmark to RF and from the Brainstruc centre (R155-2015-2666 and R328-2019-546) and a professorship grant (R310-2018-3713) funded by the Lundbeck Foundation to PN. 


\section{Author contributions}

PN and RF conceived the project, JAL designed the expression constructs and transient transfection screens with $\mathrm{CN}$, and $\mathrm{CN}$ established the BacMam expression system with support and guidance of HHG and RH. CN expressed and purified the protein with help of MH, JAL and PN. RKF also purified the protein. CN, RKF and JAL prepared cryo-EM grids, $\mathrm{CN}$ and RKF performed data processing, model refinement and validation with support and advice of JLK and JAL. The uptake assay was set-up and optimized by LLR and the final thallium uptake experiments of the wt NKCC1 and mutants were performed by $\mathrm{CN}$ under guidance of LLR and RF. Molecular dynamics simulations were done by YW and KLL. The manuscript was drafted by CN. All authors commented on the manuscript.

\section{Conflict of interest}

The authors declare no conflict of interest.

\section{Figure Legends:}

\section{Main text Figures}

Fig. 1 Overview of hNKCC1 structure. A) EM density of the transmembrane domain of

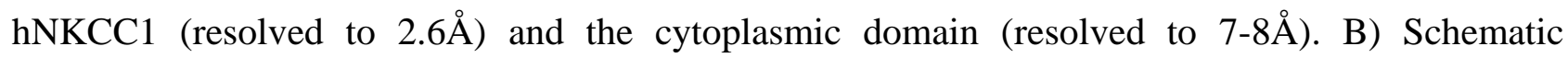
representation of the NKCC1 structure (LeuT fold). Scaffold helices are presented in wheat, bundle helices in cyan and the remaining helices presented in grey. C) Surface representation of the transmembrane domain of $\mathrm{NKCC} 1$ with lipid molecules localized at the dimerization interface (shown in spheres) and the three cholesterol binding sites (shown in spheres). In the inset, a representative density for a lipid molecule is presented. D) TM11 and TM12 from each protomer are presented together with the lipid molecules present at the dimerization interface. E, F, G) Densities for cholesterol binding site 1 , site 2 and potential site 3 are presented together with the modelled cholesterol hemisuccinate molecules. 
bioRxiv preprint doi: https://doi.org/10.1101/2021.11.11.468215; this version posted November 12, 2021. The copyright holder for this

Fig. 2 Sodium binding site. A) The sodium binding site in hNKCC1. The ion has trigonalbipyramidal coordination by five ligands. Scaffold helices are presented in wheat and bundle helices are presented in cyan; the sodium ion is presented as a purple sphere and coordinating residues are presented as sticks. B) KCC1 does not bind sodium due to a G-A substitution on TM8. Additionally, the helix is moved 2-3 away when compared with hNKCC1. C) The sodium binding site in MhsT. The ion is solvated and therefore, it has distorted octahedral coordination by five amino acid residues on TM1 and TM8 and a water molecule acting as the sixth ligand. D) Sequence alignment of the sodium site of the CCC transporters. The G-A substitution of KCC1-4 on TM8 is responsible for abolishment of sodium binding. E) Three potential intracellular exit pathways predicted by MOLE 2.5.

Fig. 3 Intracellular sodium release pathway. A) The intracellular sodium release pathway of hNKCC1. The pathway is filled with water-molecules (red spheres) and lined with two negatively charged glutamate residues (Glu429 and Glu431). B) The intracellular sodium release pathway in MhsT filled with water molecules that solvate the sodium ion. C) Sequence alignment of the intracellular part of TM5 and of TM1a of CCC transporters. The sodium-dependent CCC transporters contain two conserved glutamate and a glutamine residue within TM5 and a positively charged lysine and arginine residues on TM1a. D) Transport kinetics and relative initial transport rates of wild-type hNKCC1 and NKCC1 with a mutation within the potential sodium release pathway (E429A, E431A, E431Q) with and without addition of bumetanide; mean $\pm \mathrm{SEM}, \mathrm{n}=3$ independent experiments. In example of individual traces, fluorescence intensity is normalized to the average initial baseline period (without $\mathrm{Tl}^{+}$) for each individual cell line. In summary data, transport rates are normalized to individual NKCC1 expression per cell line and subsequently normalized to wild-type NKCC1 without bumetanide. E) Substrate release order determined by MD simulations. The $\mathrm{Cl}^{-}$bound at $\mathrm{Cl} 2$ leaves first, then the $\mathrm{Na}^{+}$ion, followed by $\mathrm{K}^{+}$and $\mathrm{Cl}^{-}$from the main binding site.

Fig. 4 Coordination network within the main binding pocket characterized for A) The main binding site of hNKCC. The binding pocket accommodates a potassium and chloride ion coordinated by TM3 from the scaffold domain (wheat) and TM1, TM6 and TM7 from the bundle domain (cyan). The density of the ions and residues important for substrate coordination is presented. B) MhsT in complex with L-tryptophan and two sodium ions. Even though the transporter translocates significantly different substrates than the SLC12 transporters, the 
bioRxiv preprint doi: https://doi.org/10.1101/2021.11.11.468215; this version posted November 12, 2021. The copyright holder for this

coordination network remains similar. The substrates bridge interactions between TM3 from the scaffold domain (wheat) and TM1, TM6 and TM7 from the bundle domain (cyan). C) Sequence alignment of the crucial amino acid residue on TM3 of CCC transporters. In contrast to other members of the SLC12 family that contain a tyrosine residue coordinating the $\mathrm{K}^{+}$ion at this position, hNCC contains a histidine residue that in its charged state could substitute the potassium ion. D) Transport kinetics and relative initial transport rates of wild-type hNKCC1 and NKCC1 with a mutation within the K- and Cl1-binding pocket (Y383F, Y383S, Y533F and Y533E) with and without addition of bumetanide; mean \pm SEM, $n=3$ independent experiments. See Fig 3 legend for normalization approaches.

Fig. 5 Coordination network between TM2-TM10 and the unwound part of TM6 in A) Cl2 binding site with the density map. The chloride ion is coordinated by the scaffold helix TM10 (wheat color) and the unwound part of TM6 belonging to the bundle domain (cyan color). B) LeuT in complex with L-leucine and sodium C, D) Sequence alignment of residues linking TM2 and TM10 and residues within the $\mathrm{Cl} 2$ binding site. E) Transport kinetics and relative initial transport rates of wild-type $\mathrm{hNKCC1}$ and $\mathrm{NKCC1}$ with a mutation within the $\mathrm{Cl} 2$ site (E429A, E431A, E431Q) with and without addition of bumetanide; mean \pm SEM, $n=3$ independent experiments. See Fig 3 legend for normalization approaches.

\section{Extended View Figures}

Fig. EV1 Processing of cryo-EM datasets 1 and 2 in Relion. Representative cryo-EM micrographs and two-dimensional class averages are shown for both datasets as well as the processing strategies used to obtain a $2.6 \AA$ structure of the transmembrane domain of hNKCC1.

Fig. EV2 Processing of the third cryo-EM dataset of hNKCC1 in Relion and CryoSPARC3. Representative cryo-EM micrographs, two-dimensional class averages and the processing strategy used to obtain the final structure of the transmembrane domain of hNKCC1.

Fig. EV3 Cryo-EM structure of hNKCC1 in complex with sodium, potassium and chloride ions. A) Gold-standard Fourier shell correlation curves between the two half maps with the final resolution at $\mathrm{F}=0.143$. B) Local resolution estimations throughout the determined transmembrane domain of hNKCC1. C) Cryo-EM map of the cytoplasmic domain of hNKCC1 with the Danio 
bioRxiv preprint doi: https://doi.org/10.1101/2021.11.11.468215; this version posted November 12, 2021. The copyright holder for this

rerio NKCC1 model docked (PDB: 6NPJ). D) Representative densities of the different transmembrane helices of molecule A of hNKCC1.

Fig. EV4 Expression, purification and functional studies of hNKCC1. A) Purification of hNKCC1 transporter expressed in HEK293 $\mathrm{GnTl}^{-}$cells. The protein used for structure determination was purified by Strep-Tactin purification, $\mathrm{Ni}^{2+}$ - ion affinity chromatography (SDSPAGE 1) followed by size exclusion chromatography (SDS-PAGE 2 and size exclusion chromatogram). B) Initial rate of $\mathrm{Tl}^{+}$transport in non-transfected cells (with and without bumetanide) as well as in cells transfected with wild-type hNKCC1 (with and without bumetanide). C) Representative western blotting of $\mathrm{NKCC} 1$ in total and biotinylated (plasma membrane) fractions of wt NKCC1 and mutant NKCC1 expressing cells. D) Surface expression of NKCC1 mutants relative to wt NKCC1.

\section{Supplementary Figures}

Fig. S1 Comparison of the hNKCC1 structure with previously published SLC12 structures. A) Comparison of protomer $\mathrm{A}$ of the determined $\mathrm{hNKCC} 1$ structure (purple) with other published NKCC1 structures (PDB codes: 6NPH, 6PZT; presented in grey) or B) with published KCC structures (PBD codes: 6KKR, 6M1Y, 6UKN, 7D14; presented in grey); C) Comparison of the determined hNKCC1dimer (cyan) with the KCC dimer (grey). D), E), F) Density for potential cholesterol binding site 1, 2, 3 and 4 in the published KCC3 structure (PDB entry: 6M22).

Fig. S2 Substrate binding of SLC12 and SLC6 transporters. Similar substrate binding in the interface between the scaffold (wheat) and bundle domain (cyan) of A) NKCC1 belonging to the SLC12 family and B) MhsT belonging to the SLC6 family.

Fig. S3 Comparison of the cryo-EM structure of hNKCC1 in the occluded, inward-facing conformation with LeuT and MhsT structures in different conformational states. A) Structural comparison of helices comprising the intracellular vestibule of the occluded, inward-facing conformation of hNKCC1 with the occluded, outward-facing conformation of LeuT (PDB entry: 2A65), the occluded, inward-facing state of MhsT with an unwound TM5 (PDB entry: 4US3; the structure was crystallized by use of the HiLiDe method), the occluded, inward-facing state of MhsT with a refolded TM5 (PDB entry: 4US4; the structure was crystallized by use of the LCP method) and the apo inward open structure of LeuT (PDB entry: 3TT3). Interactions between TM1a and 
TM5 are visualized. The hNKCC1 structure is shown in gold, whereas the other structures are presented in grey. B) The Na2 sodium binding site of the occluded, outward-facing conformation of LeuT, the occluded, inward-facing state of MhsT with an unwound TM5, the occluded, inwardfacing state of MhsT with a refolded TM5 and the apo inward open structure of LeuT.

Fig. S4 Absence of helix-breaking motifs in CCC transporters. Sequence alignment of the intracellular part of TM5 containing the GlyX 9 Pro motif in the SLC6 family with sequences of TM5 in CCC transporters.

Fig. S5 Na2 binding site in sodium-dependent and sodium (A-C) and sodium independent (DE) APC transporters. A) NSS family: MhsT (occluded inward-facing, PDB: 4US3), B) SSS family: vSGLT (inward-open, PDB: 3DH4) C) NCS1 family: Mhp1 (occluded ligand bound, PDB: 4D1A), D) BCCT family: CaiT (inward-facing, 2WsW), E) APC family: ApcT (inward-open, 3GI9), F) LAT family: BasC (inward-open, 6F2W).

Fig. S6 Lack of a sodium binding site in KCC transporters. A) Superposition of TM1 and TM8 in $\mathrm{NKCC} 1$ and $\mathrm{KCC} 1, \mathrm{~B})$ Comparison of $\mathrm{Na} 2$ binding site and the part below the $\mathrm{Na} 2$ binding site of NKCC1 and KCC1, C) Sequence alignment of the Na2 binding site and the fragment below the $\mathrm{Na} 2$ binding site of the CCC transporters. The G-A substitution of KCC1-4 on TM8 responsible for abolishment of sodium binding is highlighted as well as the two Q residues on TM1 and TM8 that are a part of the hydrogen binding network holding TM1-TM8 together.

Fig. S7 Coordination network between TM2-TM10 and the unwound part of TM6 in transporters belonging to other SLC families A) vSGLT (SLC5, 3DH4) and B) GkApcT (SLC7, 5OQT).

Fig. S4 Absence of helix-breaking motifs in CCC transporters. Sequence alignment of the intracellular part of TM5 containing the GlyX ${ }_{9}$ Pro motif in the SLC6 family with sequences of TM5 in CCC transporters.

Tables:

Table 1 Cryo-EM data collection, refinement and validation. 


\section{References}

Abraham JA, Murtola T, Schulz R, Pall S, Smith JC, Hess B, Lindahl E (2015) GROMACS: High performance molecular simulations through multi-level parallelism from laptops to supercomputers. SoftwareX 1-2: 19-25

Afonine PV, Poon BK, Read RJ, Sobolev OV, Terwilliger TC, Urzhumtsev A, Adams PD (2018) Real-space refinement in PHENIX for cryo-EM and crystallography. Acta Crystallogr D Struct Biol 74: 531-544

Arroyo JP, Kahle KT, Gamba G (2013) The SLC12 family of electroneutral cation-coupled chloride cotransporters. Mol Aspects Med 34: 288-298

Ben-Yona A, Kanner BI (2009) Transmembrane domain 8 of the \{gamma $\}$-aminobutyric acid transporter GAT-1 lines a cytoplasmic accessibility pathway into its binding pocket. $J$ Biol Chem 284: 9727-9732

Berka K, Hanak O, Sehnal D, Banas P, Navratilova V, Jaiswal D, Ionescu CM, Svobodova Varekova R, Koca J, Otyepka M (2012) MOLEonline 2.0: interactive web-based analysis of biomacromolecular channels. Nucleic Acids Res 40: W222-227

Blaesse P, Airaksinen MS, Rivera C, Kaila K (2009) Cation-chloride cotransporters and neuronal function. Neuron 61: 820-838

Brown CD, Murer $\mathrm{H}$ (1985) Characterization of a $\mathrm{Na}: \mathrm{K}: 2 \mathrm{C} 1$ cotransport system in the apical membrane of a renal epithelial cell line (LLC-PK1). J Membr Biol 87: 131-139

Chen N, Vaughan RA, Reith ME (2001) The role of conserved tryptophan and acidic residues in the human dopamine transporter as characterized by site-directed mutagenesis. J Neurochem 77: 11161127

Chew TA, Orlando BJ, Zhang J, Latorraca NR, Wang A, Hollingsworth SA, Chen DH, Dror RO, Liao M, Feng L (2019) Structure and mechanism of the cation-chloride cotransporter NKCC1. Nature 572: 488-492

Chi X, Li X, Chen Y, Zhang Y, Su Q, Zhou Q (2020) Cryo-EM structures of the full-length human KCC2 and KCC3 cation-chloride cotransporters. Cell Res

Chi X, Li X, Chen Y, Zhang Y, Su Q, Zhou Q (2021) Cryo-EM structures of the full-length human KCC2 and KCC3 cation-chloride cotransporters. Cell Res 31: 482-484

Claxton DP, Quick M, Shi L, de Carvalho FD, Weinstein H, Javitch JA, McHaourab HS (2010) Ion/substrate-dependent conformational dynamics of a bacterial homolog of neurotransmitter:sodium symporters. Nat Struct Mol Biol 17: 822-829

Coleman JA, Green EM, Gouaux E (2016) X-ray structures and mechanism of the human serotonin transporter. Nature 532: 334-339

Colmenero-Flores JM, Martinez G, Gamba G, Vazquez N, Iglesias DJ, Brumos J, Talon M (2007) Identification and functional characterization of cation-chloride cotransporters in plants. Plant J 50: 278-292

Delpire E, Gagnon KB (2011) Kinetics of hyperosmotically stimulated Na-K-2Cl cotransporter in Xenopus laevis oocytes. Am J Physiol Cell Physiol 301: C1074-1085

Delpire E, Gagnon KB (2018) $\mathrm{Na}(+)-\mathrm{K}(+)-2 \mathrm{Cl}(-)$ Cotransporter (NKCC) Physiological Function in Nonpolarized Cells and Transporting Epithelia. Compr Physiol 8: 871-901

Demian WL, Persaud A, Jiang C, Coyaud E, Liu S, Kapus A, Kafri R, Raught B, Rotin D (2019) The Ion Transporter NKCC1 Links Cell Volume to Cell Mass Regulation by Suppressing mTORC1. Cell Rep 27: 1886-1896 e1886 
bioRxiv preprint doi: https://doi.org/10.1101/2021.11.11.468215; this version posted November 12, 2021. The copyright holder for this

Doyle DA, Morais Cabral J, Pfuetzner RA, Kuo A, Gulbis JM, Cohen SL, Chait BT, MacKinnon R (1998) The structure of the potassium channel: molecular basis of $\mathrm{K}+$ conduction and selectivity. Science 280: 69-77

Ehrnstorfer IA, Geertsma ER, Pardon E, Steyaert J, Dutzler R (2014) Crystal structure of a SLC11 (NRAMP) transporter reveals the basis for transition-metal ion transport. Nat Struct Mol Biol 21: 990-996

Emsley P, Lohkamp B, Scott WG, Cowtan K (2010) Features and development of Coot. Acta Crystallogr D Biol Crystallogr 66: 486-501

Errasti-Murugarren E, Fort J, Bartoccioni P, Diaz L, Pardon E, Carpena X, Espino-Guarch M, Zorzano A, Ziegler C, Steyaert J et al (2019) L amino acid transporter structure and molecular bases for the asymmetry of substrate interaction. Nat Commun 10: 1807

Faham S, Watanabe A, Besserer GM, Cascio D, Specht A, Hirayama BA, Wright EM, Abramson J (2008) The crystal structure of a sodium galactose transporter reveals mechanistic insights into $\mathrm{Na}+$ /sugar symport. Science 321: 810-814

Fenollar-Ferrer C, Stockner T, Schwarz TC, Pal A, Gotovina J, Hofmaier T, Jayaraman K, Adhikary S, Kudlacek O, Mehdipour AR et al (2014) Structure and regulatory interactions of the cytoplasmic terminal domains of serotonin transporter. Biochemistry 53: 5444-5460

Focht D, Neumann C, Lyons J, Eguskiza Bilbao A, Blunck R, Malinauskaite L, Schwarz IO, Javitch JA, Quick M, Nissen P (2021) A non-helical region in transmembrane helix 6 of hydrophobic amino acid transporter MhsT mediates substrate recognition. EMBO J 40: e105164

Forrest LR, Kramer R, Ziegler C (2011) The structural basis of secondary active transport mechanisms. Biochim Biophys Acta 1807: 167-188

Forrest LR, Rudnick G (2009) The rocking bundle: a mechanism for ion-coupled solute flux by symmetrical transporters. Physiology (Bethesda) 24: 377-386

Gillen CM, Brill S, Payne JA, Forbush B, 3rd (1996) Molecular cloning and functional expression of the $\mathrm{K}-\mathrm{Cl}$ cotransporter from rabbit, rat, and human. A new member of the cation-chloride cotransporter family. J Biol Chem 271: 16237-16244

Goehring A, Lee CH, Wang KH, Michel JC, Claxton DP, Baconguis I, Althoff T, Fischer S, Garcia KC, Gouaux E (2014) Screening and large-scale expression of membrane proteins in mammalian cells for structural studies. Nat Protoc 9: 2574-2585

Gotfryd K, Boesen T, Mortensen JS, Khelashvili G, Quick M, Terry DS, Missel JW, LeVine MV, Gourdon P, Blanchard SC et al (2020) X-ray structure of LeuT in an inward-facing occluded conformation reveals mechanism of substrate release. Nat Commun 11: 1005

Gupta K, Donlan JAC, Hopper JTS, Uzdavinys P, Landreh M, Struwe WB, Drew D, Baldwin AJ, Stansfeld PJ, Robinson CV (2017) The role of interfacial lipids in stabilizing membrane protein oligomers. Nature 541: 421-424

Hartmann AM, Blaesse P, Kranz T, Wenz M, Schindler J, Kaila K, Friauf E, Nothwang HG (2009) Opposite effect of membrane raft perturbation on transport activity of KCC2 and NKCC1. $J$ Neurochem 111: 321-331

Hartmann AM, Nothwang HG (2014) Molecular and evolutionary insights into the structural organization of cation chloride cotransporters. Front Cell Neurosci 8: 470

Hartmann AM, Tesch D, Nothwang HG, Bininda-Emonds OR (2014) Evolution of the cation chloride cotransporter family: ancient origins, gene losses, and subfunctionalization through duplication. Mol Biol Evol 31: 434-447

Hebert SC, Mount DB, Gamba G (2004) Molecular physiology of cation-coupled Cl- cotransport: the SLC12 family. Pflugers Arch 447: 580-593 
bioRxiv preprint doi: https://doi.org/10.1101/2021.11.11.468215; this version posted November 12, 2021. The copyright holder for this

Holtzman EJ, Kumar S, Faaland CA, Warner F, Logue PJ, Erickson SJ, Ricken G, Waldman J, Kumar S, Dunham PB (1998) Cloning, characterization, and gene organization of K-Cl cotransporter from pig and human kidney and C. elegans. Am J Physiol 275: F550-564

Jaggi AS, Kaur A, Bali A, Singh N (2015) Expanding Spectrum of Sodium Potassium Chloride Cotransporters in the Pathophysiology of Diseases. Curr Neuropharmacol 13: 369-388

Ji W, Foo JN, O'Roak BJ, Zhao H, Larson MG, Simon DB, Newton-Cheh C, State MW, Levy D, Lifton RP (2008) Rare independent mutations in renal salt handling genes contribute to blood pressure variation. Nat Genet 40: 592-599

Joseph D, Pidathala S, Mallela AK, Penmatsa A (2019) Structure and Gating Dynamics of $\mathrm{Na}(+) / \mathrm{Cl}(-)$ Coupled Neurotransmitter Transporters. Front Mol Biosci 6: 80

Jungnickel KEJ, Parker JL, Newstead S (2018) Structural basis for amino acid transport by the CAT family of SLC7 transporters. Nat Commun 9: 550

Kalayil S, Schulze S, Kuhlbrandt W (2013) Arginine oscillation explains Na+ independence in the substrate/product antiporter CaiT. Proc Natl Acad Sci U S A 110: 17296-17301

Kazmier K, Sharma S, Quick M, Islam SM, Roux B, Weinstein H, Javitch JA, McHaourab HS (2014) Conformational dynamics of ligand-dependent alternating access in LeuT. Nat Struct Mol Biol 21: 472-479

Khafizov K, Perez C, Koshy C, Quick M, Fendler K, Ziegler C, Forrest LR (2012) Investigation of the sodium-binding sites in the sodium-coupled betaine transporter BetP. Proc Natl Acad Sci U S A 109: E3035-3044

Kinne R, Kinne-Saffran E, Scholermann B, Schutz H (1986) The anion specificity of the sodiumpotassium-chloride cotransporter in rabbit kidney outer medulla: studies on medullary plasma membranes. Pflugers Arch 407 Suppl 2: S168-173

Korkhov VM, Holy M, Freissmuth M, Sitte HH (2006) The conserved glutamate (Glu136) in transmembrane domain 2 of the serotonin transporter is required for the conformational switch in the transport cycle. J Biol Chem 281: 13439-13448

Koumangoye R, Bastarache L, Delpire E (2021) NKCC1: Newly Found as a Human DiseaseCausing Ion Transporter. Function (Oxf) 2: zqaa028

Krishnamurthy H, Gouaux E (2012) X-ray structures of LeuT in substrate-free outward-open and apo inward-open states. Nature 481: 469-474

Krishnamurthy H, Piscitelli CL, Gouaux E (2009) Unlocking the molecular secrets of sodiumcoupled transporters. Nature 459: 347-355

Laursen L, Severinsen K, Kristensen KB, Periole X, Overby M, Muller HK, Schiott B, Sinning S (2018) Cholesterol binding to a conserved site modulates the conformation, pharmacology, and transport kinetics of the human serotonin transporter. J Biol Chem 293: 3510-3523

Li J, Tajkhorshid E (2009) Ion-releasing state of a secondary membrane transporter. Biophys $J$ 97: L29-31

Li J, Zhao Z, Tajkhorshid E (2019) Locking Two Rigid-body Bundles in an Outward-Facing Conformation: The Ion-coupling Mechanism in a LeuT-fold Transporter. Sci Rep 9: 19479

Liu S, Chang S, Han B, Xu L, Zhang M, Zhao C, Yang W, Wang F, Li J, Delpire E et al (2019) Cryo-EM structures of the human cation-chloride cotransporter KCC1. Science 366: 505-508

Lytle C, McManus TJ, Haas M (1998) A model of Na-K-2Cl cotransport based on ordered ion binding and glide symmetry. Am J Physiol 274: C299-309

Mackenzie B, Ujwal ML, Chang MH, Romero MF, Hediger MA (2006) Divalent metal-ion transporter DMT1 mediates both $\mathrm{H}+$-coupled Fe2+ transport and uncoupled fluxes. Pflugers Arch 451: 544-558 
bioRxiv preprint doi: https://doi.org/10.1101/2021.11.11.468215; this version posted November 12, 2021. The copyright holder for this preprint (which was not certified by peer review) is the author/funder, who has granted bioRxiv a license to display the preprint in perpetuity. It is made available under aCC-BY-NC 4.0 International license.

Malinauskaite L, Quick M, Reinhard L, Lyons JA, Yano H, Javitch JA, Nissen P (2014) A mechanism for intracellular release of $\mathrm{Na}+$ by neurotransmitter/sodium symporters. Nat Struct Mol Biol 21: 1006-1012

Malinauskaite L, Said S, Sahin C, Grouleff J, Shahsavar A, Bjerregaard H, Noer P, Severinsen K, Boesen T, Schiott B et al (2016) A conserved leucine occupies the empty substrate site of LeuT in the $\mathrm{Na}(+)$-free return state. Nat Commun 7: 11673

Markadieu N, Delpire E (2014) Physiology and pathophysiology of SLC12A1/2 transporters. Pflugers Arch 466: 91-105

Monette MY, Forbush B (2012) Regulatory activation is accompanied by movement in the C terminus of the Na-K-Cl cotransporter (NKCC1). J Biol Chem 287: 2210-2220

Nakane T, Kimanius D, Lindahl E, Scheres SH (2018) Characterisation of molecular motions in cryo-EM single-particle data by multi-body refinement in RELION. Elife 7

Payne JA (2012) Molecular operation of the cation chloride cotransporters: ion binding and inhibitor interaction. Curr Top Membr 70: 215-237

Penmatsa A, Wang KH, Gouaux E (2013) X-ray structure of dopamine transporter elucidates antidepressant mechanism. Nature 503: 85-90

Perez C, Koshy C, Yildiz O, Ziegler C (2012) Alternating-access mechanism in conformationally asymmetric trimers of the betaine transporter BetP. Nature 490: 126-130

Punjani A, Rubinstein JL, Fleet DJ, Brubaker MA (2017) cryoSPARC: algorithms for rapid unsupervised cryo-EM structure determination. Nat Methods 14: 290-296

Race JE, Makhlouf FN, Logue PJ, Wilson FH, Dunham PB, Holtzman EJ (1999) Molecular cloning and functional characterization of KCC3, a new K-Cl cotransporter. Am J Physiol 277: C1210-1219 Reid MS, Kern DM, Brohawn SG (2020) Cryo-EM structure of the potassium-chloride cotransporter KCC4 in lipid nanodiscs. Elife 9

Rohou A, Grigorieff N (2015) CTFFIND4: Fast and accurate defocus estimation from electron micrographs. J Struct Biol 192: 216-221

Russell JM (2000) Sodium-potassium-chloride cotransport. Physiol Rev 80: 211-276

Scheres SH (2012) RELION: implementation of a Bayesian approach to cryo-EM structure determination. J Struct Biol 180: 519-530

Sen N, Shi L, Beuming T, Weinstein H, Javitch JA (2005) A pincer-like configuration of TM2 in the human dopamine transporter is responsible for indirect effects on cocaine binding. Neuropharmacology 49: 780-790

Shaffer PL, Goehring A, Shankaranarayanan A, Gouaux E (2009) Structure and mechanism of a $\mathrm{Na}$-independent amino acid transporter. Science 325: 1010-1014

Shahsavar A, Stohler P, Bourenkov G, Zimmermann I, Siegrist M, Guba W, Pinard E, Sinning S, Seeger MA, Schneider TR et al (2021) Structural insights into the inhibition of glycine reuptake. Nature 591: 677-681

Shaikh SA, Tajkhorshid E (2010) Modeling and dynamics of the inward-facing state of a Na+/Cldependent neurotransmitter transporter homologue. PLoS Comput Biol 6

Simon DB, Karet FE, Hamdan JM, DiPietro A, Sanjad SA, Lifton RP (1996a) Bartter's syndrome, hypokalaemic alkalosis with hypercalciuria, is caused by mutations in the $\mathrm{Na}-\mathrm{K}-2 \mathrm{Cl}$ cotransporter NKCC2. Nat Genet 13: 183-188

Simon DB, Nelson-Williams C, Bia MJ, Ellison D, Karet FE, Molina AM, Vaara I, Iwata F, Cushner HM, Koolen M et al (1996b) Gitelman's variant of Bartter's syndrome, inherited hypokalaemic alkalosis, is caused by mutations in the thiazide-sensitive $\mathrm{Na}-\mathrm{Cl}$ cotransporter. Nat Genet 12: 24-30 
bioRxiv preprint doi: https://doi.org/10.1101/2021.11.11.468215; this version posted November 12, 2021. The copyright holder for this

Somasekharan S, Tanis J, Forbush B (2012) Loop diuretic and ion-binding residues revealed by scanning mutagenesis of transmembrane helix 3 (TM3) of Na-K-Cl cotransporter (NKCC1). J Biol Chem 287: 17308-17317

Sucic S, Paczkowski FA, Runkel F, Bonisch H, Bryan-Lluka LJ (2002) Functional significance of a highly conserved glutamate residue of the human noradrenaline transporter. J Neurochem 81: 344354

Tavoulari S, Margheritis E, Nagarajan A, DeWitt DC, Zhang YW, Rosado E, Ravera S, Rhoades E, Forrest LR, Rudnick G (2016) Two Na+ Sites Control Conformational Change in a Neurotransmitter Transporter Homolog. J Biol Chem 291: 1456-1471

Turner RJ, George JN (1988) Ionic dependence of bumetanide binding to the rabbit parotid Na/K/Cl cotransporter. J Membr Biol 102: 71-77

Wahlgren WY, Dunevall E, North RA, Paz A, Scalise M, Bisignano P, Bengtsson-Palme J, Goyal $\mathrm{P}$, Claesson E, Caing-Carlsson R et al (2018) Substrate-bound outward-open structure of a $\mathrm{Na}(+)-$ coupled sialic acid symporter reveals a new $\mathrm{Na}(+)$ site. Nat Commun 9: 1753

Warmuth S, Zimmermann I, Dutzler R (2009) X-ray structure of the C-terminal domain of a prokaryotic cation-chloride cotransporter. Structure 17: 538-546

Watanabe A, Choe S, Chaptal V, Rosenberg JM, Wright EM, Grabe M, Abramson J (2010) The mechanism of sodium and substrate release from the binding pocket of vSGLT. Nature 468: 988991

Weyand S, Shimamura T, Yajima S, Suzuki S, Mirza O, Krusong K, Carpenter EP, Rutherford NG, Hadden JM, O'Reilly J et al (2008) Structure and molecular mechanism of a nucleobase-cationsymport-1 family transporter. Science 322: 709-713

Williams CJ, Headd JJ, Moriarty NW, Prisant MG, Videau LL, Deis LN, Verma V, Keedy DA, Hintze BJ, Chen VB et al (2018) MolProbity: More and better reference data for improved all-atom structure validation. Protein Sci 27: 293-315

Xie Y, Chang S, Zhao C, Wang F, Liu S, Wang J, Delpire E, Ye S, Guo J (2020) Structures and an activation mechanism of human potassium-chloride cotransporters. Sci Adv 6

Yamashita A, Singh SK, Kawate T, Jin Y, Gouaux E (2005) Crystal structure of a bacterial homologue of Na+/Cl--dependent neurotransmitter transporters. Nature 437: 215-223

Yan R, Zhang Y, Li Y, Xia L, Guo Y, Zhou Q (2020) Structural basis for the recognition of SARSCoV-2 by full-length human ACE2. Science 367: 1444-1448

Yang X, Wang Q, Cao E (2020) Structure of the human cation-chloride cotransporter NKCC1 determined by single-particle electron cryo-microscopy. Nat Commun 11: 1016

Zhang S, Zhou J, Zhang Y, Liu T, Friedel P, Zhuo W, Somasekharan S, Roy K, Zhang L, Liu Y et al (2021) The structural basis of function and regulation of neuronal cotransporters NKCC1 and KCC2. Commun Biol 4: 226

Zhang YW, Tavoulari S, Sinning S, Aleksandrova AA, Forrest LR, Rudnick G (2018) Structural elements required for coupling ion and substrate transport in the neurotransmitter transporter homolog LeuT. Proc Natl Acad Sci U S A 115: E8854-E8862

Zhao Y, Terry D, Shi L, Weinstein H, Blanchard SC, Javitch JA (2010) Single-molecule dynamics of gating in a neurotransmitter transporter homologue. Nature 465: 188-193

Zimanyi CM, Guo M, Mahmood A, Hendrickson WA, Hirsh D, Cheung J (2020) Structure of the Regulatory Cytosolic Domain of a Eukaryotic Potassium-Chloride Cotransporter. Structure 

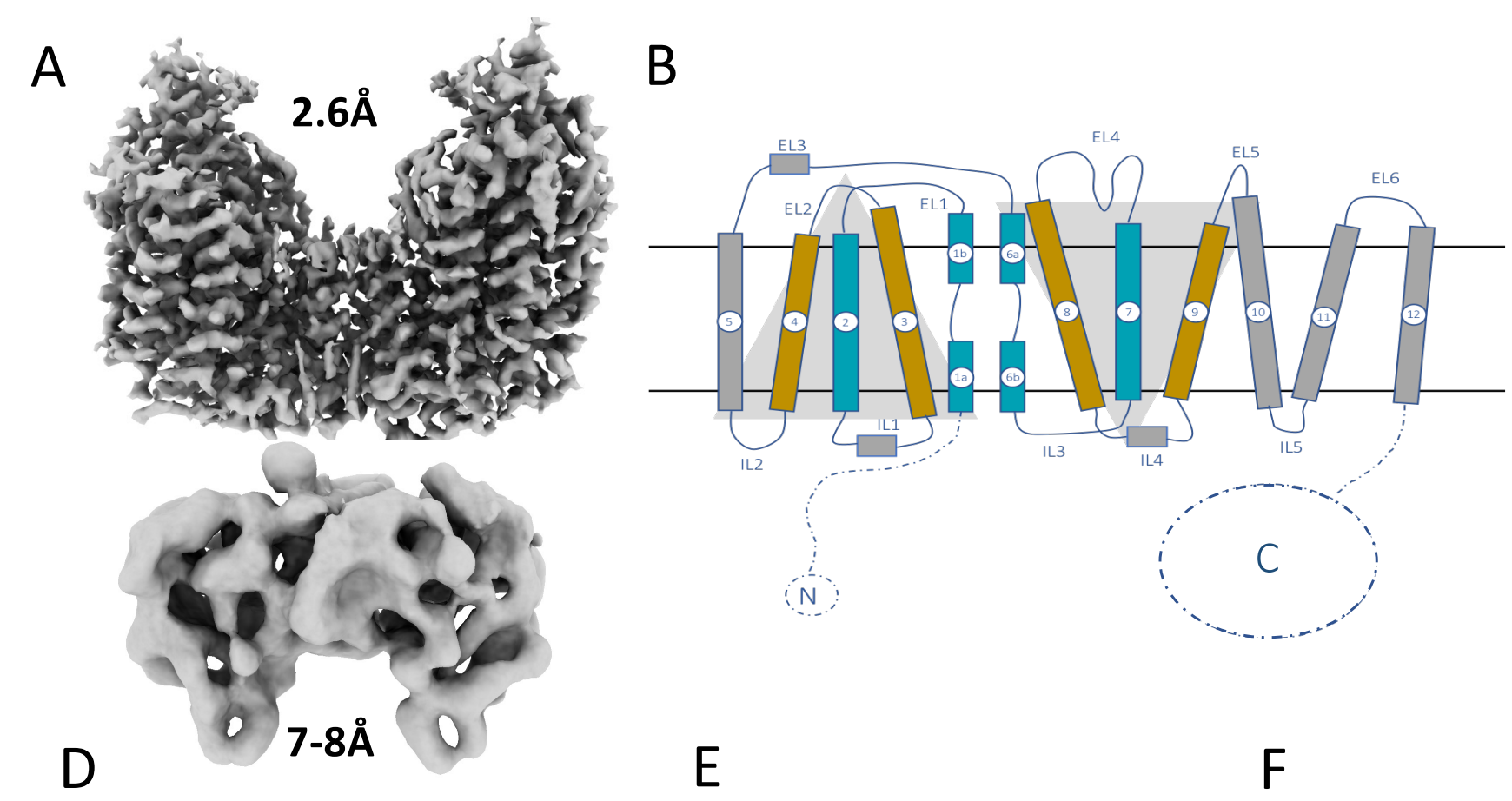

E
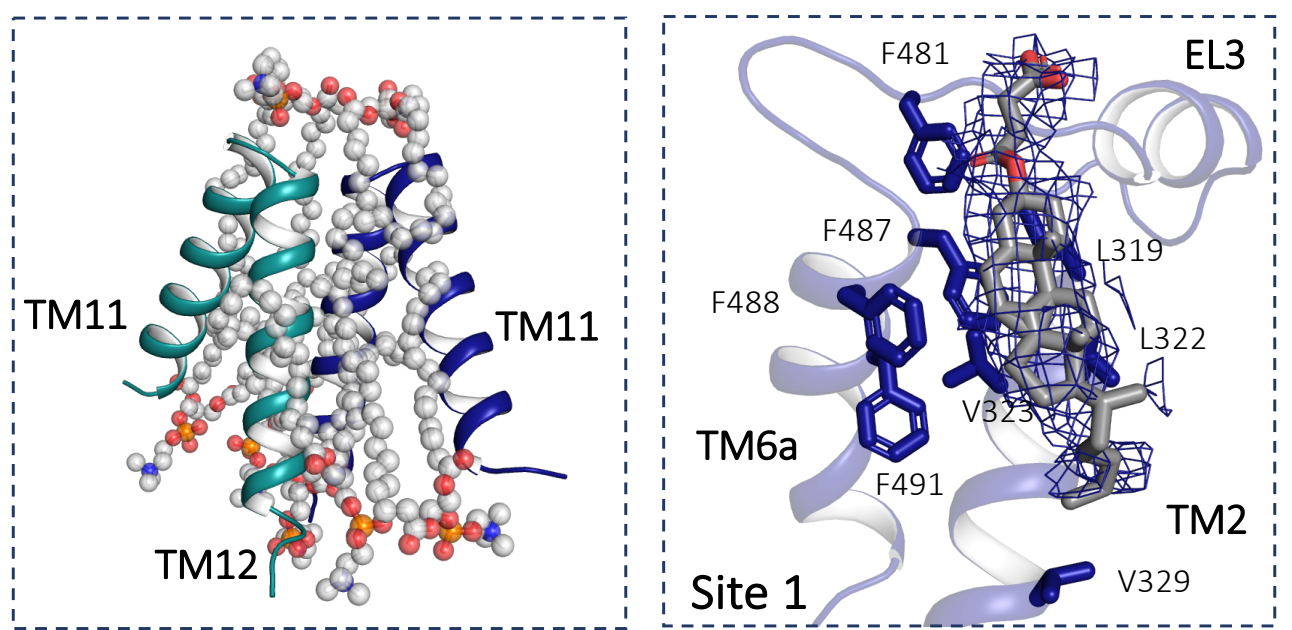

$\mathrm{F}$
C Fig. 1

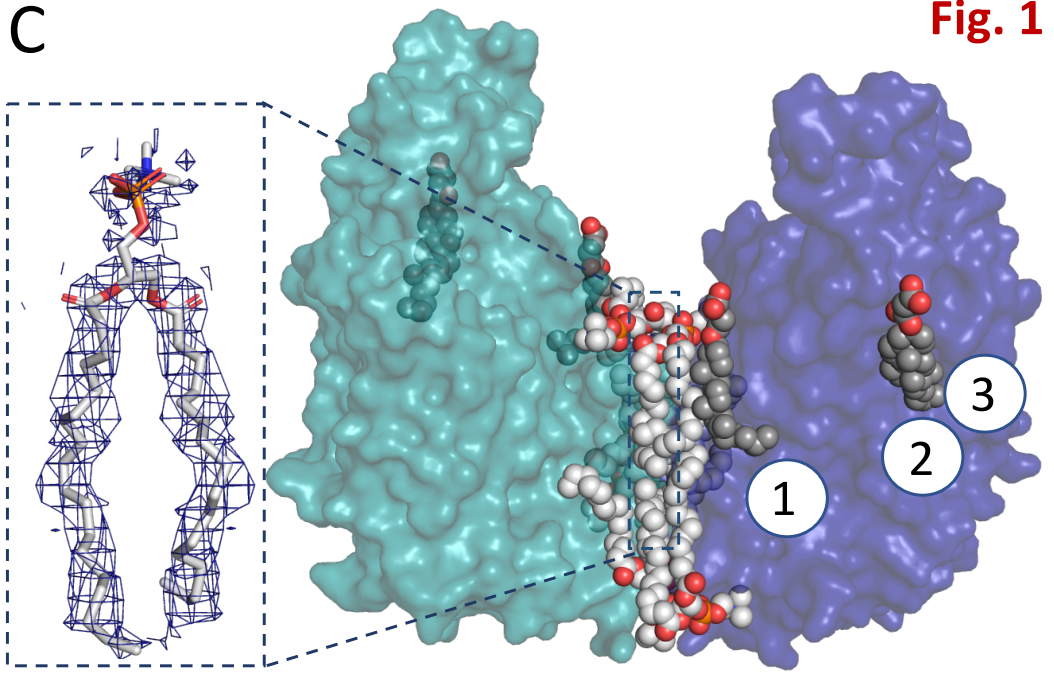

G

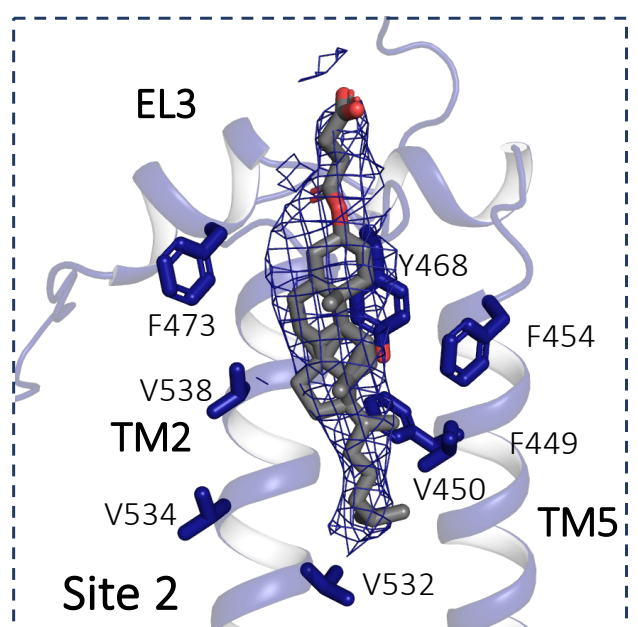


A
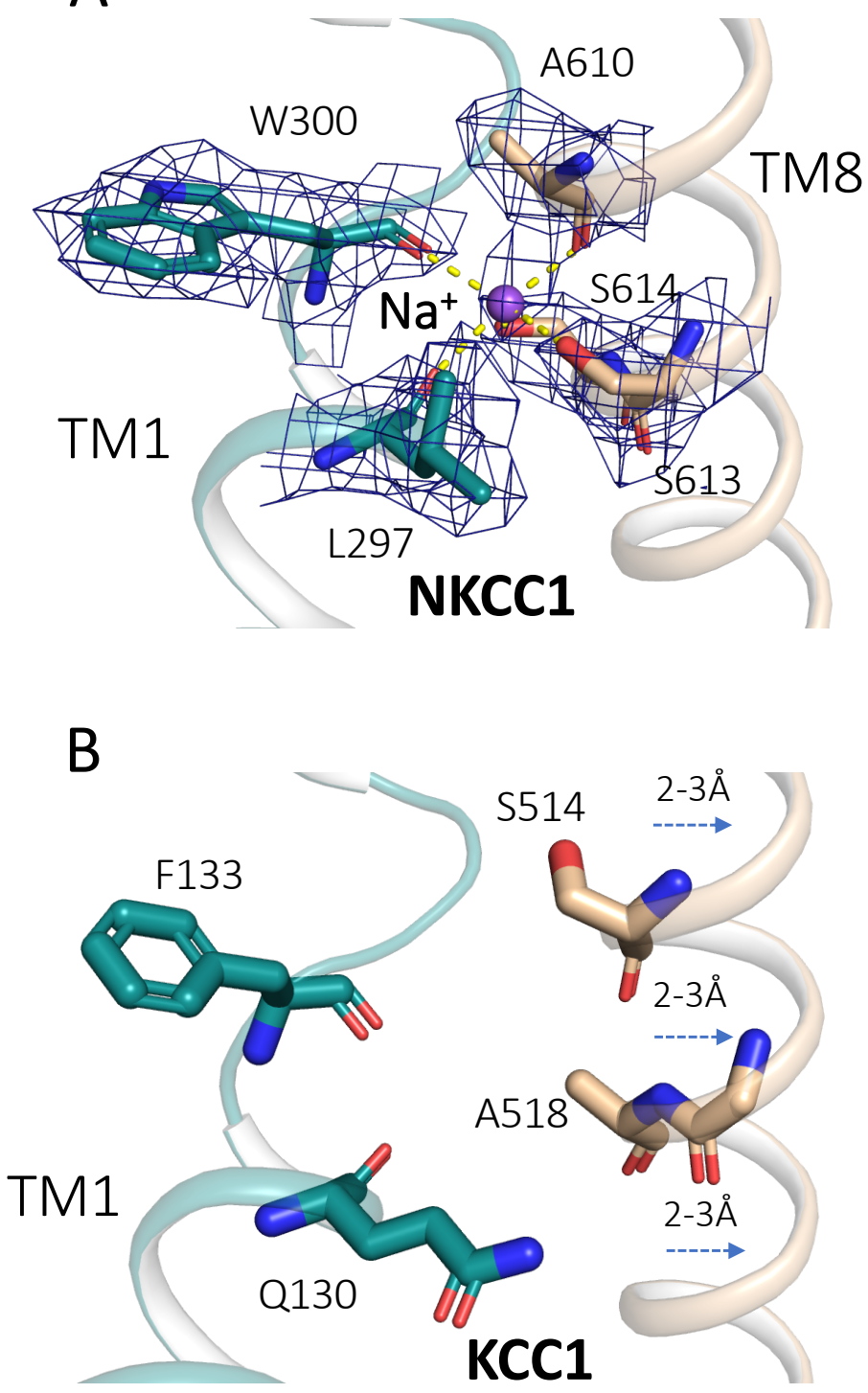

C

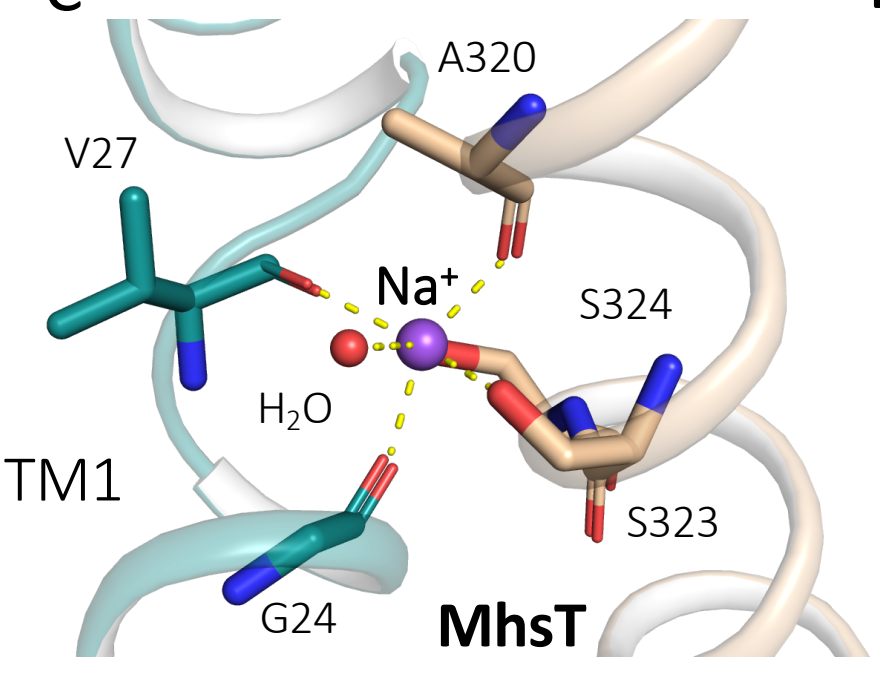

E

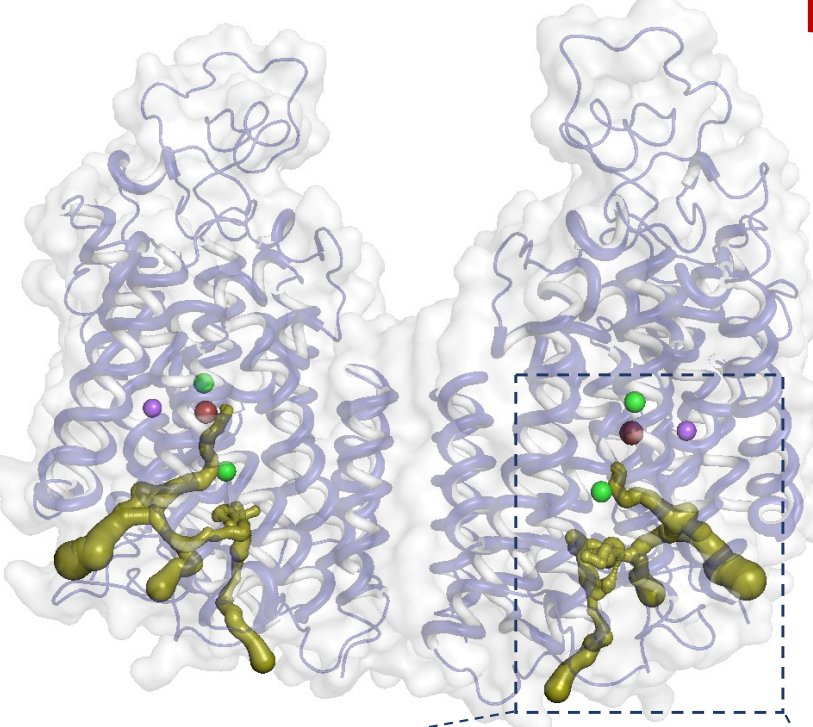

D

\begin{tabular}{|lll|}
\hline \multicolumn{3}{|c|}{ Na binding site } \\
NKCC1 & $S^{613}$ & $S^{614}$ \\
NKCC2 & $S^{506}$ & $S^{507}$ \\
NCC & $S^{467}$ & $S^{468}$ \\
KCC1 & $G^{517}$ & $A^{518}$ \\
KCC2 & $G^{520}$ & $A^{521}$ \\
KCC3 & $G^{582}$ & $A^{583}$ \\
KCC4 & $G^{517}$ & $A^{518}$ \\
\hline
\end{tabular}

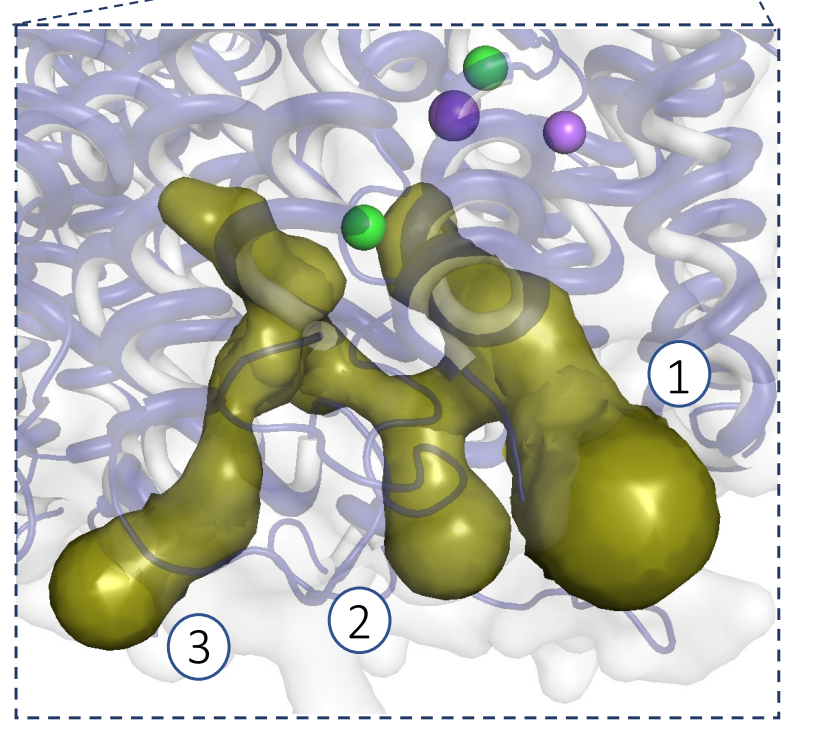

Fig. 2 
A

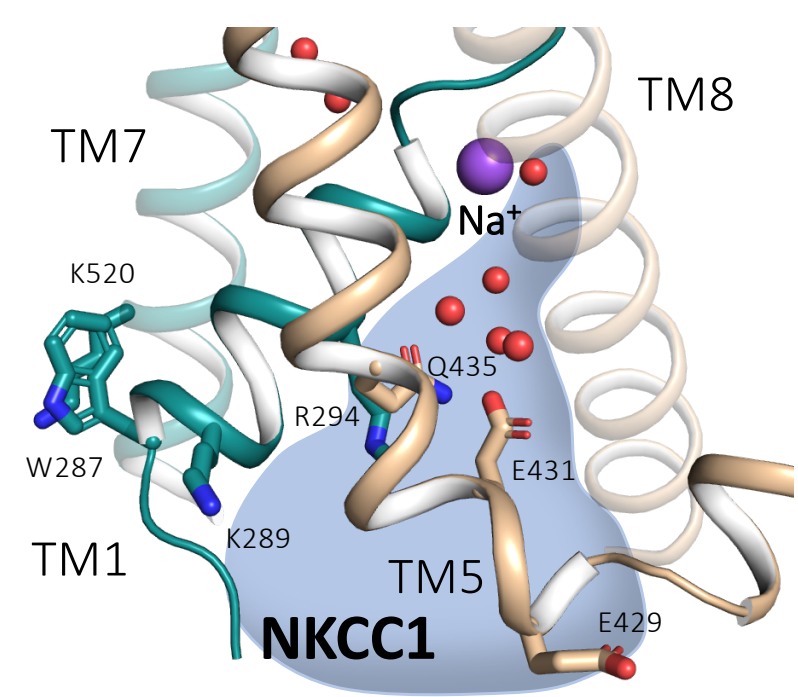

D

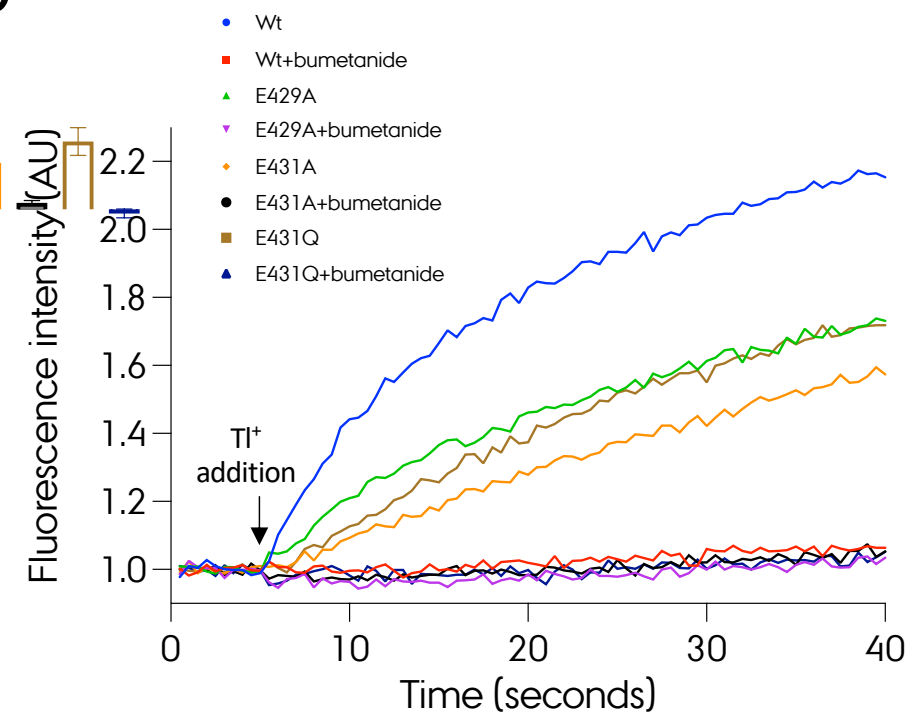

B
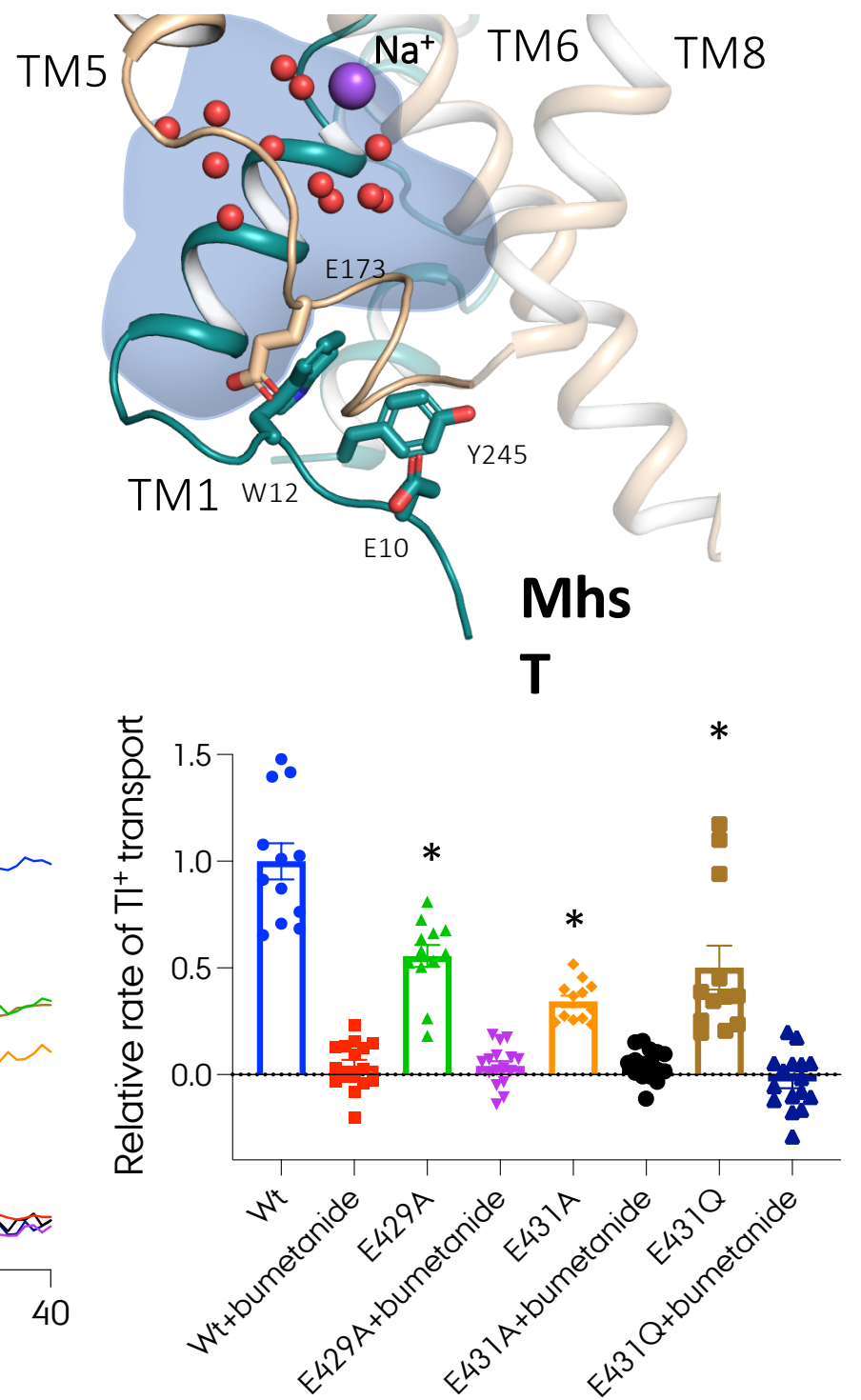

C

\begin{tabular}{llllllllll|lll} 
hNKCC1/1-1212 & 427 & G M M E & W & E & A & K & A & Q & I & 436
\end{tabular} hNKCC2/1-1099 319 G M \begin{tabular}{llll|l|l|llll|lll} 
hNCC/1-1021 & 278 & G & M E & W & E & S & K & A & Q & V & 287
\end{tabular} hKCC1/1-1085 269 G V hKCC3/1-1150 336 G V R Y V N K F A S 345 hKCC2/1-1139 271 G V K hKCC4/1-1083 269 G V K

$\begin{array}{llllllllllll}\text { hNKCC1/1-1212 } & 287 & \text { W I } & \text { K } & \text { G V L V } & \text { R C M } 297\end{array}$ $\begin{array}{lllllllllllllll}\text { hNKCC2/1-1099 } & 179 & \text { W } & \text { V } & \text { K } & \text { G V V L } & \text { V } & \text { R } & \text { C M } & 189\end{array}$ $\begin{array}{lllllllllll}\text { hNCC/1-1021 } & 138 & \text { W V V K G V M V R C M } 148\end{array}$ hKCC1/1-1085 $120 \quad$ T L M G V Y L P C L 130 $\begin{array}{lllllllllll}\text { hKCC3/1-1150 } & 187 & \text { T } & \text { F M G V Y L } & \text { P C L } 187\end{array}$ $\begin{array}{llllllll}\text { hKCC2/1-1139 } 122 & \text { T F M G V Y L P C L } 132\end{array}$ $\begin{array}{lllllllllll}\text { hKCC4/1-1083 } & 120 & \text { T } & \text { F I } & \text { G V Y Y L P C L } & 130\end{array}$

E

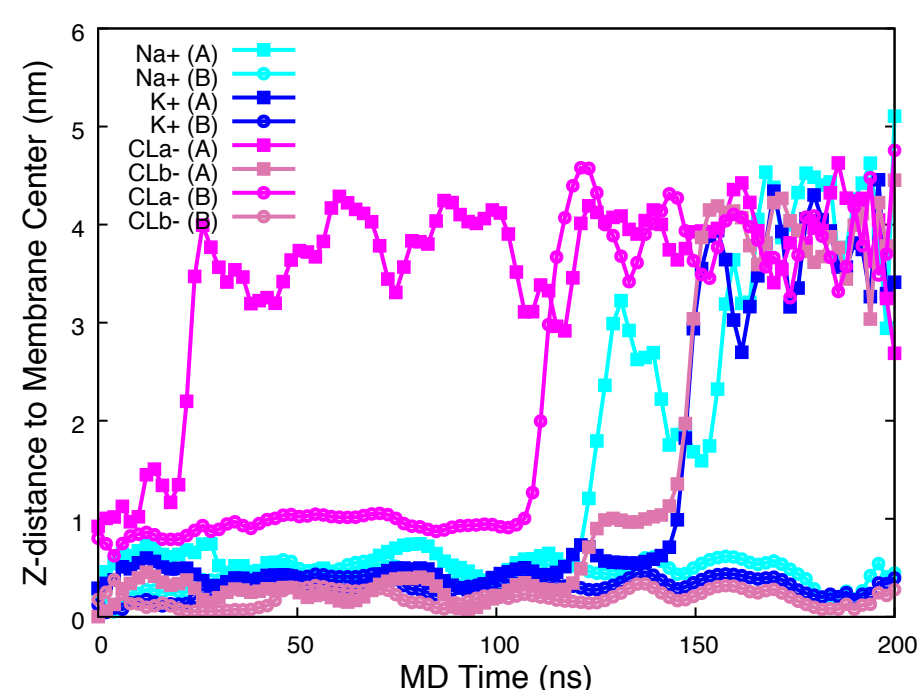



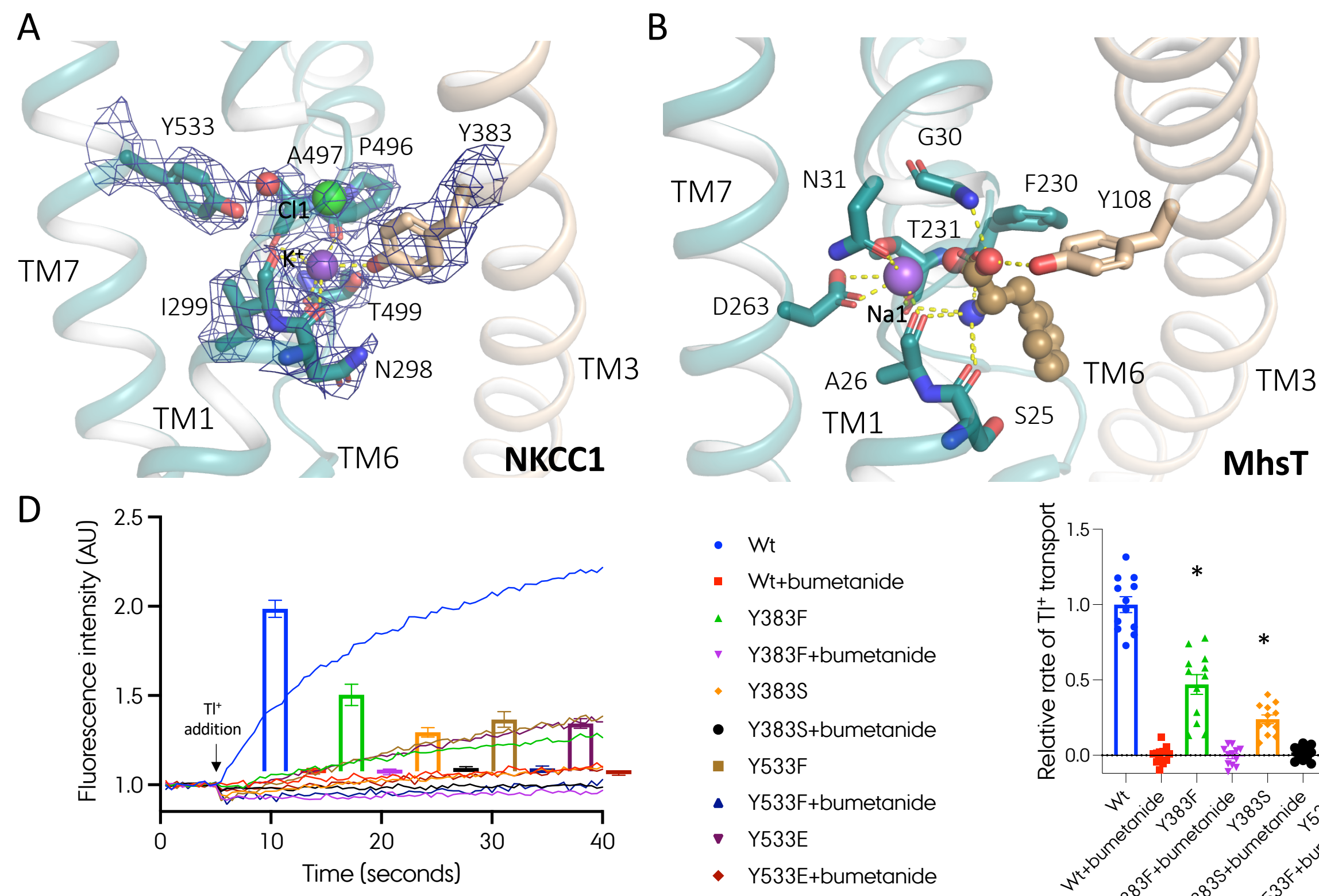

C
\begin{tabular}{|ll|}
\hline NKCC1 & $Y^{383}$ \\
NKCC2 & $Y^{275}$ \\
\hline NCC & $H^{234}$ \\
\hline KCC1 & $Y^{216}$ \\
KCC2 & $Y^{218}$ \\
KCC3 & $Y^{283}$ \\
KCC4 & $Y^{216}$ \\
\hline
\end{tabular}

\section{- Wt}

- Wt+bumetanide

- Y383F

v Y383F+bumetanide

- Y383S

- Y383S+bumetanide

- $\mathrm{Y} 533 \mathrm{~F}$

- Y533F+bumetanide

- $Y 533 E$

- Y533E+bumetanide

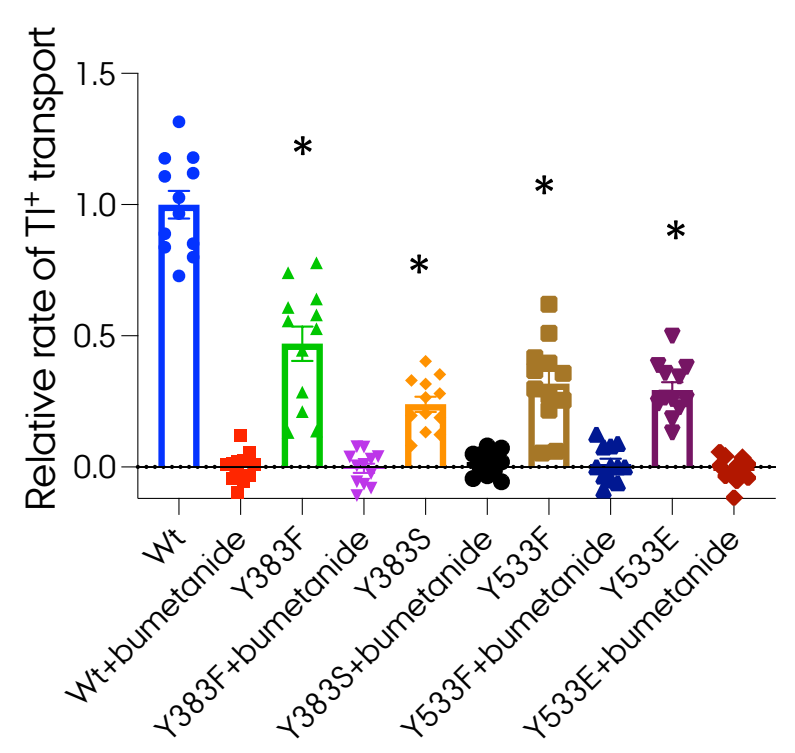


A

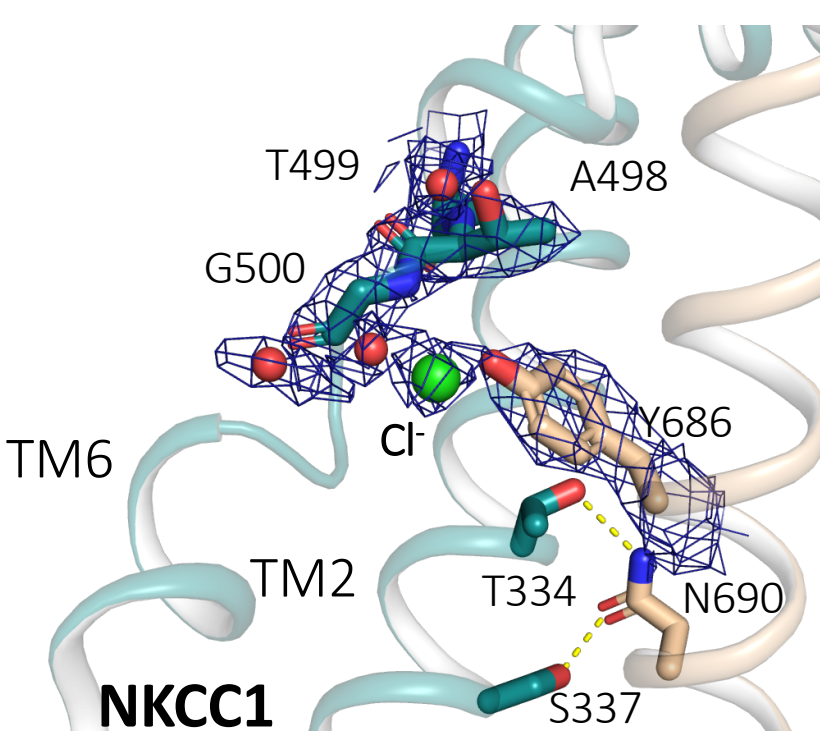

D

\begin{tabular}{|lcccc|}
\hline \multicolumn{5}{c|}{ Cl2 binding site } \\
NKCC1 & $A^{498}$ & $T^{499}$ & $G^{500}$ & $Y^{686}$ \\
NKCC2 & $A^{391}$ & $T^{392}$ & $G^{393}$ & $Y^{579}$ \\
NCC & $A^{351}$ & $T^{352}$ & $G^{353}$ & $Y^{540}$ \\
KCC1 & $V^{431}$ & $T^{432}$ & $G^{433}$ & $Y^{589}$ \\
KCC2 & $V^{434}$ & $T^{435}$ & $G^{436}$ & $Y^{592}$ \\
KCC3 & $V^{496}$ & $T^{497}$ & $G^{498}$ & $Y^{654}$ \\
KCC4 & $V^{431}$ & $T^{432}$ & $G^{433}$ & $Y^{589}$ \\
\hline
\end{tabular}

B TM10

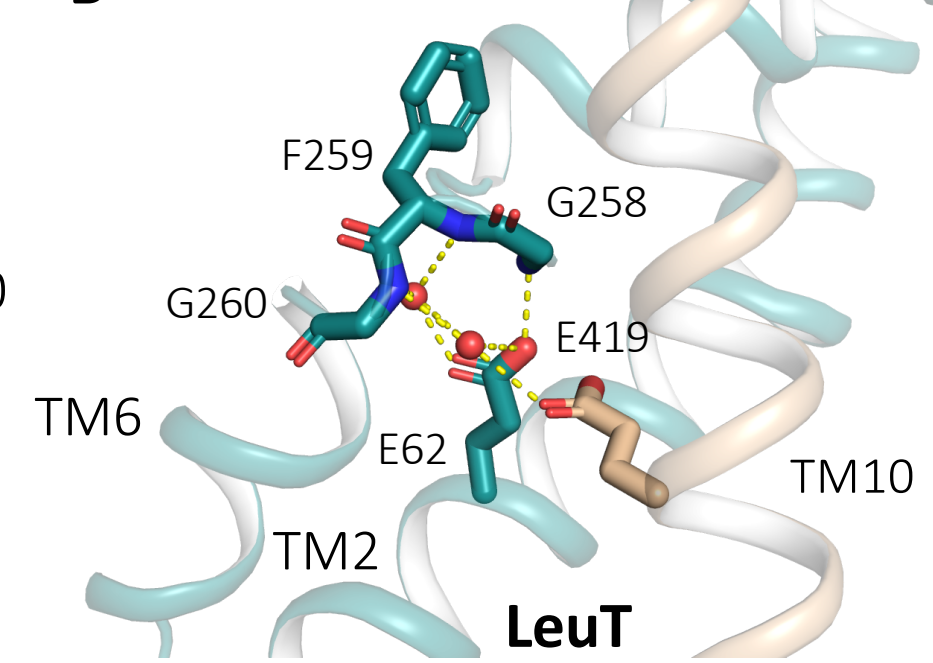

E

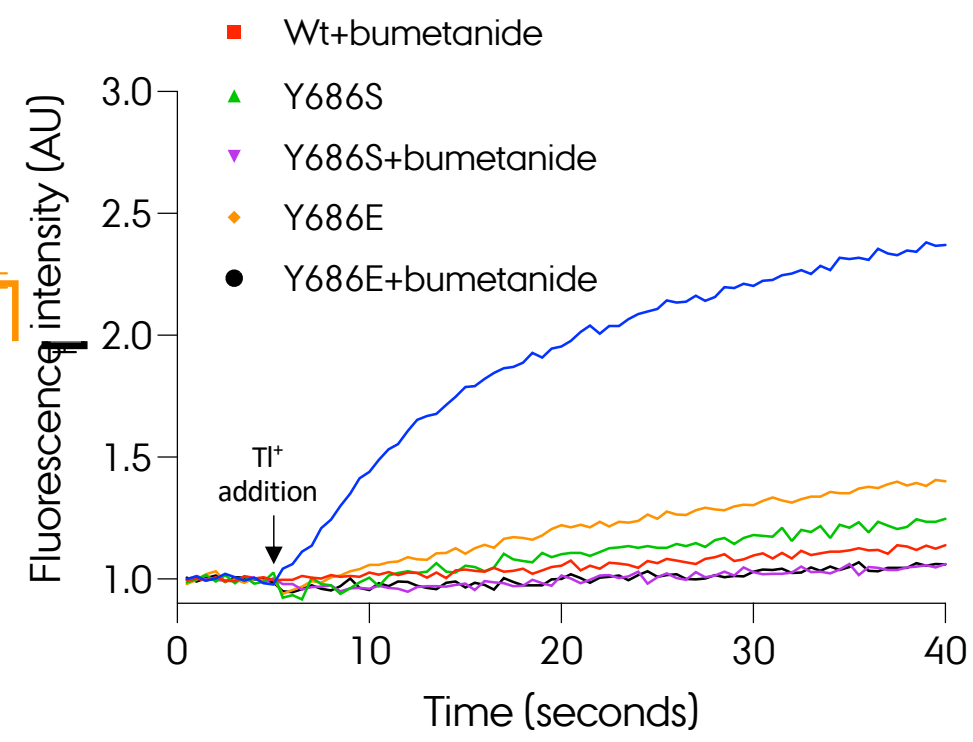

Fig. 5

C

\begin{tabular}{|llll|}
\hline \multicolumn{4}{c}{ TM2-TM10 } \\
NKCC1 & $\mathrm{T}^{334}$ & $\mathrm{~S}^{337}$ & $\mathrm{~N}^{690}$ \\
NKCC2 & $\mathrm{T}^{226}$ & $\mathrm{~S}^{229}$ & $\mathrm{~N}^{583}$ \\
NCC & $\mathrm{T}^{185}$ & $\mathrm{~S}^{188}$ & $\mathrm{~N}^{544}$ \\
KCC1 & $\mathrm{T}^{167}$ & $\mathrm{~S}^{170}$ & $\mathrm{~N}^{593}$ \\
KCC2 & $\mathrm{T}^{169}$ & $\mathrm{~S}^{172}$ & $\mathrm{~N}^{596}$ \\
KCC3 & $\mathrm{T}^{234}$ & $\mathrm{~S}^{237}$ & $\mathrm{~N}^{658}$ \\
KCC4 & $\mathrm{T}^{167}$ & $\mathrm{~S}^{170}$ & $\mathrm{~N}^{593}$ \\
\hline
\end{tabular}

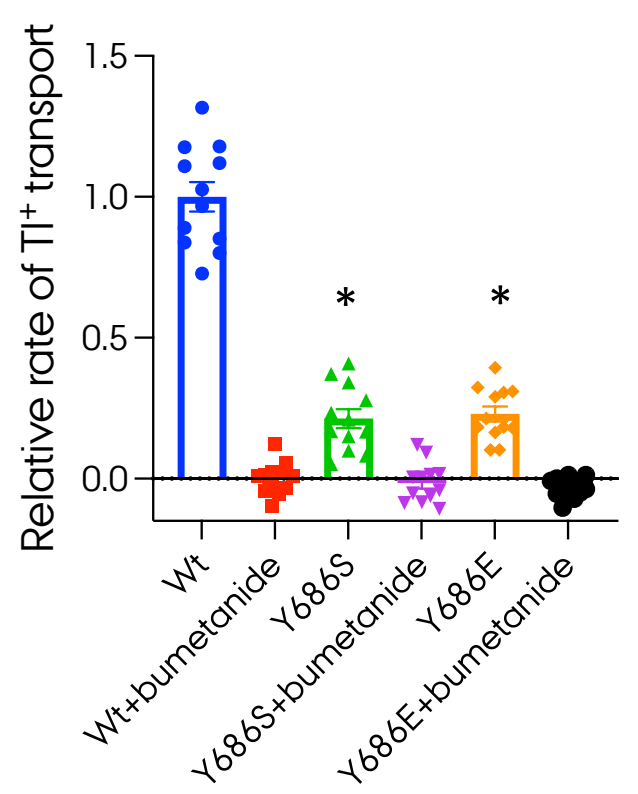




\begin{tabular}{|c|c|c|c|c|c|c|}
\hline \multirow{2}{*}{$\begin{array}{l}\text { Data collection and } \\
\text { processing }\end{array}$} & \multirow[t]{2}{*}{ Dataset 1} & \multirow[t]{2}{*}{ Dataset 2} & \multirow[t]{2}{*}{ Dataset 3} & \multirow{2}{*}{$\begin{array}{l}\text { Combined } \\
\text { map }\end{array}$} & \multicolumn{2}{|l|}{ Model refinement } \\
\hline & & & & & Model composition & \\
\hline Magnification & $165000 x$ & $165000 x$ & $130000 x$ & & $\overline{\text { Protein residues }}$ & 946 \\
\hline Voltage (kV) & 300 & 300 & 300 & & Ligands & 8 \\
\hline Microscope & Titan Krios2 & Titan Krios2 & Titan Krios & & B factors $\left(\AA^{2}\right)$ & \\
\hline Electron exposure $\left(\mathrm{e}-/ \AA^{2}\right)$ & 40.12 & 39.78 & 60.438 & & Protein & 75.09 \\
\hline Defocus range $(\mu \mathrm{m})$ & $0.6-1.6$ & $0.6-1.6$ & $0.5-2.4$ & & Ligand & 59.30 \\
\hline Pixel size & 0.507 & 0.507 & 0.829 & & R.m.s. deviations & \\
\hline Camera & $\begin{array}{c}\text { Gatan K3 Summit } \\
\text { camera }\end{array}$ & $\begin{array}{c}\text { Gatan K3 Summit } \\
\text { camera }\end{array}$ & $\begin{array}{c}\text { Gatan K3 Summit } \\
\text { camera }\end{array}$ & & \multirow{2}{*}{$\begin{array}{l}\text { Bond lengths }(\AA) \\
\text { Bond angles }\left(^{\circ}\right) \\
\text { Ramachandran plot }\end{array}$} & 0.004 \\
\hline Number of movies & 10335 & 9464 & 6490 & & & $0.6 \angle 2$ \\
\hline Symmetry imposed & $\mathrm{C} 2$ & $\mathrm{C} 2$ & $\mathrm{C} 2$ & $\mathrm{C} 2$ & Favored (\%) & 95.46 \\
\hline Initial particle images (no.) & 1002976 & 1566691 & 2710603 & & Allowed (\%) & 4.54 \\
\hline Final particle images (no.) & 81946 & 56870 & 119975 & 256791 & Disallowed (\%) & 0 \\
\hline Map resolution $(\AA ̊)$ & 2.79 & 2.93 & 2.96 & 2.55 & & \\
\hline FSC threshold & 0.143 & 0.143 & 0.143 & 0.143 & & \\
\hline Map resolution range ( $\AA$ ) & & & & $2.4-3.6$ & & \\
\hline
\end{tabular}

